\title{
On the incorporation of strontium into the crystal structure of bredigite: structural effects and phase transition
}

\author{
Volker Kahlenberg $^{1}$ (1) $\cdot$ Lukas Prosser $^{1} \cdot$ Michael F. Salzmann $^{1} \cdot$ Clivia Hejny $^{1}$
}

Received: 24 September 2021 / Accepted: 10 November 2021 / Published online: 3 December 2021

(c) The Author(s) 2021

\begin{abstract}
Sr-substitution in the crystal structure of bredigite has been studied in detail. Samples of a hypothetical solid-solution series with nominal composition $\mathrm{Ca}_{7-\mathrm{x}} \mathrm{Sr}_{\mathrm{x}} \mathrm{Mg}\left[\mathrm{SiO}_{4}\right]_{4}(\mathrm{x}=0,2, \ldots, 7)$ have been prepared from sinter reactions in the temperature range between 1275 and $1325^{\circ} \mathrm{C}$ and characterized using powder and single-crystal X-ray diffraction. Synthesis runs between $\mathrm{x}=1$ and $\mathrm{x}=4$ resulted in compounds with increasing $\mathrm{Sr}$ contents, for which single-crystal diffraction studies revealed the following $\mathrm{Sr} /(\mathrm{Sr}+\mathrm{Ca})$ atomic ratios: $0.133,0.268,0.409$ and 0.559 . They are isostructural to the pure calcium end-member $(\mathrm{x}=0)$ and adopt the orthorhombic space group Pnnm. Evolution of the unit-cell parameters and cell volumes of the solid-solution series are defined by linear or nearly linear trends when plotted against the $\mathrm{Sr} / \mathrm{Sr}+\mathrm{Ca})$ atomic ratio. Replacement of calcium with strontium atoms on the different sites shows clear preferences for specific positions. For the experiment with $\mathrm{x}=5$, formation of bredigite-related single-crystals with $\mathrm{Sr} / \mathrm{Sr}+\mathrm{Ca})=0.675$ was observed. These samples, however, exhibited a halved $c$ lattice parameter when compared with the corresponding value in the Pnnm structure, pointing to a compositionally induced phase transition somewhere in region between $\mathrm{Sr} / \mathrm{Sr}+\mathrm{Ca})=0.559$ and 0.675. The crystal structure of this new phase with composition $\mathrm{Ca}_{2.32} \mathrm{Sr}_{4.82} \mathrm{Mg}_{0.86}\left[\mathrm{SiO}_{4}\right]_{4}$ was successfully determined in space group Pbam. Basic crystallographic data are as follows: $a=18.869(2) \AA, b=6.9445(8) \AA, c=5.5426(6) \AA, \mathrm{V}=726.28(14) \AA^{3}$, $\mathrm{Z}=2$. Structure determination was accomplished using charge flipping. Subsequent least-squares refinements resulted in a residual of $\mathrm{R}(|\mathrm{F}|)=2.70 \%$ for 822 independent reflections and 87 parameters. The Pbam- and the Pnnm-structures are in a group-subgroup relationship and topologically related. Both are based on so-called pinwheel-like $\mathrm{MSi}_{6} \mathrm{O}_{24}$ clusters consisting of a central magnesium-dominated $\left[\mathrm{MO}_{6}\right]$-octahedron as well as six attached $\left[\mathrm{SiO}_{4}\right]$-tetrahedra. The clusters are linked into chain-like elements running along [001]. Linkage between the chains is provided by mixed $\mathrm{Sr} / \mathrm{Ca}$ positions with 6 to 10 oxygen ligands. Differences between the two phases result from changes in $\mathrm{Sr}$-Ca site occupancies in combination with displacements of the atoms and tilts of the tetrahedra. The distortion pattern has been studied using group-theoretical methods including mode analysis. Notably, for the samples with $x=6$ and $x=7$-the latter corresponding to the hypothetical pure strontium end-member composition—no bredigite-type phases could be identified, indicating that there is an upper limit for the Sr-uptake.
\end{abstract}

Keywords Bredigite $\cdot$ Crystal structure $\cdot$ Phase transition $\cdot$ Strontium incorporation

\section{Introduction}

Bredigite (ideally $\mathrm{Ca}_{7} \mathrm{Mg}\left[\mathrm{SiO}_{4}\right]_{4}$ ) is an exotic phase, presently known from only a handful of localities listed in the mindat.org database (http://www.mindat.org, accessed May

Editorial handling: H. Poellmann

Volker Kahlenberg

volker.kahlenberg@uibk.ac.at

1 Institute of Mineralogy and Petrography, University of Innsbruck, Innrain 52, 6020 Innsbruck, Austria 3rd, 2021) including some famous areas for the discovery of new minerals such as the Hatrurim complex, Negev Desert, Israel (Sharygin et al. 2008; Kahlenberg et al. 2019) or the Ettringer Bellerberg volcano in the Eifel region, Germany (Blaß and Kruijen 2014). Despite of its rareness, bredigite occurs in quite a number of different petrological settings all of which are related to pyrometamorphism (Tilley and Vincent 1948; Bridge 1966; Grapes 2011; Žáček et al. 2015; Kahlenberg et al. 2019). However, there are also bredigite samples in nature that are of anthropogenic origin due to combustion processes in coal mine dumps, which triggered 
thermal alteration of pre-existing sedimentary rocks (Sharygin 2010).

On the other hand, synthetic equivalents to bredigite have been described from several products related to the field of applied mineralogy. For example, bredigite is a component in steel and stainless steel making wastes (Bodor et al. 2013). Recent investigations (Bodor et al. 2013; Chiang et al. 2013) studied the carbonation of different compounds from these slags with the purpose of $\mathrm{CO}_{2}$ sequestration. Interestingly, bredigite exhibited the highest $\mathrm{CO}_{2}$-uptake of all relevant crystalline phases. Furthermore, bredigitecontaining slags have been investigated as potential hydraulic binders (Pontikes et al. 2013; Ferreira Neto et al. 2017).

Another field of application where bredigite comes into play are bone replacement and bone formation ceramics or coatings, since bredigite combines excellent biocompatibility with apatite mineralization ability and mechanical properties close to cortical bone (Wu et al. 2005; Razavi et al. 2013; Yi et al. 2014; Dezfuli et al. 2017; Huang et al. 2017).

Structural characterization of bredigite-in early phase equilibrium studies also referred to as "phase T" (Sharp et al. 1960; Gutt 1961) - has seen several trials and tribulations that have been summarized by Moseley and Glasser (1981). Since the early publication of Tilley and Vincent (1948) bredigite was believed to be isostructural with $\alpha^{\prime}-\mathrm{Ca}_{2} \mathrm{SiO}_{4}$ for more than 25 years. However, already Douglas (1952) pointed out that the powder diffraction patterns of both compounds showed pronounced differences and concluded that their identity cannot be established with absolute certainty. The final proof that phase $\mathrm{T}$ is a stoichiometric $\mathrm{Mg}$-containing compound with idealized composition $\mathrm{Ca}_{7} \mathrm{Mg}\left[\mathrm{SiO}_{4}\right]_{4}$ and not isotypic with $\alpha$ ' $-\mathrm{Ca}_{2} \mathrm{SiO}_{4}$ was delivered by Saalfeld (1974) and the crystal-structure analysis of Moore and Araki (1976). The Moore and Araki model was slightly modified by Kahlenberg et al. (2019). Though principally correct, the previous study had described the bredigite structure in an unnecessarily low acentric Pnn 2 space-group symmetry.

So far, information on cation substitutions into the bredigite structure is scarce. According to Moseley and Glasser $(1981,1982), \mathrm{Mg}^{2+}$ ions cannot be replaced by divalent cations such as $\mathrm{Zn}^{2+}, \mathrm{Co}^{2+}$ or $\mathrm{Ni}^{2+}$ between 1300 and $1350^{\circ}$ $\mathrm{C}$ using solid-state reactions. By contrast, it is well known that larger amounts of manganese can be found in bredigites from metallurgical slags (Moore and Araki 1976). Quite surprisingly, however, the targeted incorporation of $\mathrm{Mn}^{2+}$ by the abovementioned synthesis route was not possible either. Replacements of larger alkaline earth cations ( $\mathrm{Sr}, \mathrm{Ba}$ ) for $\mathrm{Ca}$ were seemingly more successful. When compared with the data for the pure calcium end-member, samples with nominal compositions $\left.\mathrm{Ca}_{6.5} \mathrm{Sr}_{0.5} \mathrm{Mg}\left[\mathrm{SiO}_{4}\right]_{4}, \mathrm{Ca}_{6} \mathrm{SrMg}_{[} \mathrm{SiO}_{4}\right]_{4}$ and $\mathrm{Ca}_{6.5} \mathrm{Ba}_{0.5} \mathrm{Mg}\left[\mathrm{SiO}_{4}\right]_{4}$ showed a significant increase in the values of the unit-cell volumes pointing to a successful substitution among the larger divalent cations. However, due to the limitations of structural studies based on X-ray powder diffraction data in the era before the Rietveld method became a standard tool for this purpose, Moseley and Glasser (1982) did not perform any more detailed crystallographic investigations on their polycrystalline samples.

The main goals of the present study were (i) to investigate the potential solid-solution series $\left(\mathrm{Ca}_{7-\mathrm{x}} \mathrm{Sr}_{\mathrm{x}}\right) \mathrm{Mg}\left[\mathrm{SiO}_{4}\right]_{4}$ in more detail and (ii) to present structural data on the individual members of the series.

\section{Experimental details}

Starting materials were based on mixtures of $\mathrm{CaCO}_{3}$ (Merck, > 99.0\%), $\mathrm{SrCO}_{3}$ (Merck, > 99.0\%), $\mathrm{SiO}_{2}$ (Alfa Aesar, 99.5\%), and $\mathrm{MgO}$ (Merck, 99\%). Eight different samples of $2 \mathrm{~g}$ each were prepared for a hypothetical solidsolution series with nominal composition $\mathrm{Ca}_{7-\mathrm{x}} \mathrm{Sr}_{\mathrm{x}} \mathrm{Mg}\left[\mathrm{SiO}_{4}\right]_{4}$ $(\mathrm{x}=0,1, \ldots, 7)$. For easy reference, we will denote these mixtures Bred-0 to Bred-7. Before weighing on an analytical balance the educts were dried for $12 \mathrm{~h}$ at $300{ }^{\circ} \mathrm{C}$ in order to eliminate any physically adsorbed water. Since magnesia is known to be gradually hydrated to $\mathrm{Mg}(\mathrm{OH})_{2}$ after longer storage periods, the material taken from the bottle was pre-heated at $700{ }^{\circ} \mathrm{C}$ for $24 \mathrm{~h}$. A planetary mill operated at $600 \mathrm{rpm}$ was used for homogenization for $45 \mathrm{~min}$. under ethanol. The resulting slurry was dried at $50{ }^{\circ} \mathrm{C}$ to remove the alcohol completely and stored in a desiccator. Subsequently, the educts were pressed into pellets (approximately $0.5 \mathrm{~g}$, having a diameter of $12 \mathrm{~mm}$ and a thickness of about $3 \mathrm{~mm}$ ). Two pellets for each composition were placed on platinum foils contained in alumina ceramic combustion boats, transferred to a resistance heated chamber furnace and heated from ambient temperature with a heating ramp of $50^{\circ} \mathrm{C} / \mathrm{h}$ to $1275^{\circ} \mathrm{C}$. The porous sinter-pellets were removed after $100 \mathrm{~h}$ and quenched in air. The samples were re-ground, re-pressed and fired for a second time at $1325{ }^{\circ} \mathrm{C}$, respectively. After the second cycle the compact sinter tablets were crushed in an agate mortar and split into two parts.

One half was further pulverized and prepared for powder $\mathrm{X}$-ray diffraction (PXRD). The patterns of the bulk material from the synthesis products were recorded with a Bruker D8-Discover diffractometer in Bragg-Brentano geometry. The device is equipped with a primary beam $\mathrm{Ge}(111)$ monochromator, primary and secondary Soller slits and a LYNXEYETM silicon strip detector. Data have been acquired in the range between $10^{\circ}$ and $90^{\circ} 2 \theta$ with a step size of $0.01^{\circ}$ and a measurement time of $2.5 \mathrm{~s}$ per step. The $\mathrm{Cu}-\mathrm{X}$-ray tube was operated with $40 \mathrm{kV}$ and $40 \mathrm{~mA}$. The software DIFFRAC.EVA (Bruker-AXS 2020) in combination with the ICDD PDF-4 + database version 4.2103 was used for qualitative phase analysis of the powder diffraction patterns which revealed the multi-phase character of the products. 
Subsequent quantitative phase analysis (QPA) of the crystalline products was based on the Rietveld method performed with the program DIFFRAC.TOPAS (Bruker-AXS 2018). Peak profiles were modeled using the fundamental parameter approach. For simulation of the background Chebychev polynomials were selected.

From the remaining part of each sample small singlecrystals up to $100 \mu \mathrm{m}$ in diameter could be extracted which were further checked by polarization microscopy. Notably, many crystals were intensively twinned when observed between crossed-polarizers. Crystals of sufficient optical quality were fixed on the top of glass fibers with nail polish and further examined on a Rigaku Oxford Diffraction Gemini R Ultra diffractometer equipped with a four-circle kappa-goniometer and a Ruby CCD detector. Measurements were conducted with Mo-radiation. For the samples Bred-1 to Bred-5, crystals showing bredigite-related unit cells could be found. From each of these sets, the crystal with the best overall diffraction quality was finally selected for full data collection (see Table 1). The CrysAlisPRO software package (Rigaku 2015) was employed to process the data. After indexing, the diffraction patterns were integrated. Further data reduction included Lorentz and polarization as well as an absorption correction. Diffraction symmetry of all crystals conformed to the orthorhombic Laue group $2 / \mathrm{m}$ $2 / m 2 / m$. For the crystals from samples Bred- 1 to Bred-4 the values of the lattice parameters indicated the presence of bredigite-type phases isostructural to the pure calcium endmember. Consequently, the structure model of Kahlenberg et al. (2019) for a natural bredigite in space group Pnnm was used as a starting point for structure analysis. The crystals retrieved from sample Bred-5 showed a halved $c$ lattice parameter when compared with the corresponding value in bredigite, pointing to a compositionally induced phase transition. The crystal structure of this compound was successfully determined in space group Pbam using charge flipping (program SUPERFLIP; Palatinus and Chapuis 2007).

Full-matrix least-squares refinements for all five samples were performed with the program SHELX-97 (Sheldrick 2008) embedded in the software suite WinGX (Farrugia 1999). X-ray scattering factors were taken from the International Tables for Crystalllography, Vol. C (Wilson 1992). The optimization calculations including fractional atomic coordinates, anisotropic displacement parameters and calcium-strontium as well as calcium-magnesium atom populations on the relevant sites converged to residual values for $R(|\mathrm{~F}|)$ between 2.70 and $4.80 \%$. During the refinements, no constraints concerning the bulk chemistry of the crystals were applied. However, full

Table 1 Crystal structure refinement details for the samples retrieved from the synthesis experiments Bred-1 to Bred-5

\begin{tabular}{|c|c|c|c|c|c|}
\hline Sample & Bred-1 & Bred-2 & Bred-3 & Bred-4 & Bred-5 \\
\hline \multicolumn{6}{|l|}{ Crystal data: } \\
\hline Empirical formula & $\mathrm{Ca}_{6.11} \mathrm{Sr}_{0.94} \mathrm{Mg}_{0.95}\left[\mathrm{SiO}_{4}\right]_{4}$ & $\mathrm{Ca}_{5.16} \mathrm{Sr}_{1.89} \mathrm{Mg}_{0.95}\left[\mathrm{SiO}_{4}\right]_{4}$ & $\mathrm{Ca}_{4.20} \mathrm{Sr}_{2.91} \mathrm{Mg}_{0.90}\left[\mathrm{SiO}_{4}\right]_{4}$ & $\mathrm{Ca}_{3.14} \mathrm{Sr}_{3.98} \mathrm{Mg}_{0.89}\left[\mathrm{SiO}_{4}\right]_{4}$ & $\mathrm{Ca}_{2.32} \mathrm{Sr}_{4.82} \mathrm{Mg}_{0.86}\left[\mathrm{SiO}_{4}\right]_{4}$ \\
\hline $\mathrm{Sr} /(\mathrm{Sr}+\mathrm{Ca})$ atomic ratio & 0.133 & 0.268 & 0.409 & 0.559 & 0.675 \\
\hline $\mathrm{Z}$ & 4 & 4 & & 4 & 2 \\
\hline Formula weight (g/Mol) & 718.49 & 763.59 & 812.95 & 863.32 & 905.1 \\
\hline Space group & Pnnm & Pnnm & Pnnm & Pnnm & Pbam \\
\hline \multirow[t]{3}{*}{ Unit cell dimensions: } & $18.4340(14)$ & $18.5732(16)$ & $18.661(2)$ & $18.783(4)$ & $18.869(2)$ \\
\hline & $6.7778(5)$ & $6.8272(6)$ & $6.8671(8)$ & $6.9066(12)$ & $6.9445(8)$ \\
\hline & $10.9079(9)$ & $10.9443(11)$ & $10.9707(13)$ & $11.028(2)$ & $5.5426(6)$ \\
\hline Volume $\left(\AA^{3}\right)$ & $1362.85(18)$ & $1387.8(2)$ & 1405.9(3) & $1430.6(5)$ & $726.28(14)$ \\
\hline Mass density (calculated, $\mathrm{g} / \mathrm{cm}^{3}$ ) & 3.50 & 3.66 & 3.84 & 4.01 & 4.14 \\
\hline Linear absorption coefficient $\left(\mathrm{mm}^{-1}\right)$ & 6.5 & 9.6 & 13.0 & 16.3 & 19.0 \\
\hline $\mathrm{F}(000)$ & 1413 & 1481 & 1556 & 1634 & 1696 \\
\hline \multicolumn{6}{|l|}{ Data collection: } \\
\hline Crystal size $\left(\mathrm{mm}^{3}\right)$ & $0.06 \times 0.12 \times 0.14$ & $0.06 \times 0.11 \times 0.16$ & $0.04 \times 0.07 \times 0.12$ & $0.03 \times 0.08 \times 0.12$ & $0.03 \times 0.05 \times 0.06$ \\
\hline$\Theta$-range for data collection $\left({ }^{\circ}\right)$ & 3.54 to 26.36 & 3.52 to 26.36 & 3.50 to 26.37 & 3.65 to 26.69 & 3.64 to 26.37 \\
\hline Reflections collected & 8150 & 8365 & 8742 & 8931 & 4298 \\
\hline Independent reflections & $1473 \mathrm{R}$ (int) $=4.9 \%$ & $1500 \mathrm{R}$ (int) $=4.6 \%$ & $1512 \mathrm{R}$ (int) $=5.4 \%$ & $1534 \mathrm{R}$ (int) $=5.8 \%$ & $822 \mathrm{R}($ int $)=4.7 \%$ \\
\hline \multicolumn{6}{|l|}{ Refinement: } \\
\hline Data / restraints / parameters & $1473 / 0 / 153$ & $1500 / 0 / 153$ & $1512 / 0 / 153$ & $1534 / 0 / 153$ & $822 / 0 / 87$ \\
\hline Goodness-of-fit on $\mathrm{F}^{2}$ & 1.22 & 1.19 & 1.12 & 0.99 & 1.14 \\
\hline Final $R$ indices $[\mathrm{I}>2 \sigma(\mathrm{I})]$ & $\mathrm{R} 1=3.24, \mathrm{wR} 2=7.64 \%$ & $\mathrm{R} 1=4.48, \mathrm{wR} 2=9.92 \%$ & $\mathrm{R} 1=4.02, \mathrm{wR} 2=7.58 \%$ & $\mathrm{R} 1=4.80, \mathrm{wR} 2=6.51 \%$ & $\mathrm{R} 1=2.70, \mathrm{wR} 2=6.29 \%$ \\
\hline $\mathrm{R}$ indices (all data) & $\mathrm{R} 1=3.97, \mathrm{wR} 2=7.96 \%$ & $\mathrm{R} 1=5.82, \mathrm{wR} 2=10.57 \%$ & $\mathrm{R} 1=5.39, \mathrm{wR} 2=8.36 \%$ & $\mathrm{R} 1=5.28, \mathrm{wR} 2=7.84 \%$ & $\mathrm{R} 1=3.28, \mathrm{wR} 2=6.53 \%$ \\
\hline Largest difference peak and hole $\left(\mathrm{e} / \AA^{3}\right)$ & 0.73 and -0.77 & 0.85 and -0.93 & 0.69 and -1.25 & 0.81 and -1.03 & 0.82 and -1.09 \\
\hline
\end{tabular}

All data collections were performed at $22(2){ }^{\circ} \mathrm{C}$ using Mo- $\mathrm{K}_{\alpha}$ radiation 
occupancy of the different cation positions was assumed. Notably, the resulting bulk compositions depart somewhat from ideal $\mathrm{Ca}_{7-\mathrm{x}} \mathrm{Sr}_{\mathrm{x}} \mathrm{Mg}\left[\mathrm{SiO}_{4}\right]_{4}$ and consistently exhibit less than one $\mathrm{Mg}$-atom per formula unit (see Table 1). Final coordinates, site occupancies as well as equivalent isotropic displacement parameters are given in Tables 2 and 3, respectively. Anisotropic displacement parameters are listed in the supplementary Tables S1 and S2. Selected interatomic distances are summarized in Tables 4 and 5. Figures showing structural features were prepared using the program VESTA3 (Momma and Izumi 2011). The same program was also employed for the calculation of the effective coordination numbers $(\mathrm{ECON})$ as well as volumes and distortion indices of the $\mathrm{MO}_{\mathrm{x}}$-polyhedra which can be found in Tables 4 and 5 .

\section{Results}

\section{X-ray powder diffraction and phase analysis}

Evaluation of the powder diffraction patterns confirmed the earlier observation of Moseley and Glasser (1982) that the kinetics of bredigite formation by solidstate reactions is sluggish. After two burning cycles, the bredigite yield for the pure calcium end-member composition (Bred-0) was quite low. Actually, the following phases were identified: Ca-bredigite (43 wt $\%$ ), $\beta-\mathrm{Ca}_{2} \mathrm{SiO}_{4}(29 \mathrm{wt} \%), \gamma-\mathrm{Ca}_{2} \mathrm{SiO}_{4}(18 \mathrm{wt} \%)$, merwinite (5 $\mathrm{wt} \%$ ), åkermanite (2 wt\%), periclase ( $2 \mathrm{wt} \%$ and lime (1 wt\%) (see Fig. 1a). The numbers in parentheses refer to weight percentages obtained from QPA based on the corresponding Rietveld refinements. Structure models for the individual phases were taken either from the literature or from the data reported in this paper. According to our experience the accuracy of the QPA results is estimated to be $0.5-2 \mathrm{wt} \%$. At any rate the real errors are significantly higher than those from the Rietveld analysis software reflecting only the precision of the mathematical fit between measured and calculated step intensities. For the samples Bred-1 to Bred-4, the yields for the Srbredigite phases increased with increasing Sr-content reaching $98 \mathrm{wt} \%$ for Bred-4. Within these samples, Sråkermanite $\left(\mathrm{Sr}_{2} \mathrm{MgSi}_{2} \mathrm{O}_{7}\right)$ was always observed as an impurity phase (see Fig. 1b). Notably, sample Bred-5 contained minor amounts of the Pnnm-phase (6 wt\%) in addition to the Pbam-polymorph which accounted for 90 wt $\%$ of the sample. For Bred- 6 and Bred- 7 no bredigite formation could be observed - at least within the detection limit of PXRD which is about $1 \mathrm{wt} \%$. The sample Bred-7, for instance, consisted of several Sr- and Sr-Mgsilicates including $\mathrm{Sr}_{3} \mathrm{MgSi}_{2} \mathrm{O}_{8}$ (39 wt\%), Sr-åkermanite (5 wt $\%), \alpha^{\prime}-\mathrm{Sr}_{2} \mathrm{SiO}_{4}(48 \mathrm{wt} \%)$ as well as $\beta-\mathrm{Sr}_{2} \mathrm{SiO}_{4}(8$ wt\%) (see Fig. 1c).

\section{Pnnm solid-solution series}

As mentioned above, the crystals obtained from the samples Bred-1 to Bred-4 are isotypic with bredigite, whose atomic arrangement has been already described in detail by Moore and Araki (1976) as well as Kahlenberg et al. (2019). Therefore, we will refrain from an in-depth discussion of the crystal structure but rather focus on the most important aspects. Many of the structural features described in the following paragraphs will be also of relevance for the Pbam-modification which will be addressed later.

Bredigite belongs to the group of nesosilicates and is based on so-called pinwheel-like clusters, an expression that has been coined by Moore and Araki (1976). A single pinwheel consists of a central magnesium-dominated octahedron as well as six attached $\left[\mathrm{SiO}_{4}\right]$-tetrahedra (see Fig. 2a). Within the unit-cell four of these $\mathrm{MSi}_{6} \mathrm{O}_{24}$ polyhedral microensembles (PME) can be found, each of which resides on positions with site-symmetry $2 / m$. Using the classification of Ilyushin and Blatov (2002) based on the calculation of the coordination sequences up to $\mathrm{k}=3$, the PME can be denoted as $\{6,6,18\}$. The PME are located in about $7 \AA$ wide layers which are parallel to (100). Within these slabs, chainlike elements along [001] can be identified (cf. Fig. 3a). A single chain consists of an alternating sequence of the pinwheels centered around M7 and M8, where a single octahedron shares two tetrahedra on each side with two adjacent octahedra. Linkage between proximate chains along [010] is provided by $\mathrm{M} 1$ and $\mathrm{M} 2$, whose coordination polyhedra can be described as strongly distorted trigonal antiprisms sharing common edges (for M2) or faces (for M1) with the

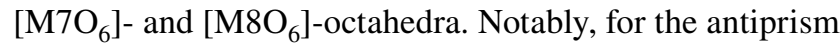
around the $\mathrm{M} 1$ position four additional $\mathrm{M}-\mathrm{O}$ bonds can be found up to $3.0 \AA$ which should be actually considered for the coordination environment. Neighboring layers, in turn, are linked by the positions M3, M4, M5, and M6 having irregular coordination environments with 7 to 9 next oxygen neighbors (see Table 4). For the Sr-richest member of the Pnnm-type solid-solution series $(\mathrm{Sr} /(\mathrm{Ca}+\mathrm{Sr})=0.559)$ minor changes in the coordination environment have been observed. Actually, the following longer bonds have to be considered as well: M4: one bond to O3 with $2.983 \AA$ and M5: two bonds to O3 with $2.949 \AA$ each as well as one bond to O6 with $2.977 \AA$. Projections of the whole crystal structure for the representative with $\mathrm{Sr} /(\mathrm{Ca}+\mathrm{Sr})=0.133$ are shown in Figs. 4a and 5a, respectively.

The substitution of a larger cation like $\mathrm{Sr}^{2+}$ for the smaller $\mathrm{Ca}^{2+}$ increases, as expected, the size of the unit-cell volume. Actually, the volume gain between Bred- 1 and Bred- 4 corresponds to $67.7 \AA^{3}$ or $4.97 \%$. As can be seen from Fig. 6 , the volume data do not exhibit a significant deviation from a linear behavior when plotted against the $\mathrm{Sr} /(\mathrm{Sr}+\mathrm{Ca})$ atomic ratio. The volume changes are also reflected in an increase of 
Table 2 Positions and Wyckoff-symbols (WS), atomic coordinates as well as site populations for the mixed positions in samples Bred- 1 to Bred-4

\begin{tabular}{|c|c|c|c|c|c|c|c|}
\hline Position, & WS & $\mathbf{x}$ & $\mathrm{y}$ & $\mathbf{z}$ & $\mathrm{Ca} / \mathrm{Sr}[\%]$ & $\mathrm{Mg} / \mathrm{Ca}[\%]$ & $\mathrm{U}(\mathrm{eq})\left[\AA^{2}\right]$ \\
\hline M1 & $2 a$ & & & & & & \\
\hline Bred-1 & & 0 & 0 & 0 & 9.4/90.6(8) & & $0.0184(3)$ \\
\hline Bred-2 & & 0 & 0 & 0 & $5.5 / 94.5(11)$ & & $0.0175(4)$ \\
\hline Bred-3 & & 0 & 0 & 0 & $0 / 100$ & & $0.0187(4)$ \\
\hline Bred-4 & & 0 & 0 & 0 & $0 / 100$ & & $0.0198(7)$ \\
\hline M2 & $2 b$ & & & & & & \\
\hline Bred-1 & & 0 & 0 & $1 / 2$ & $87.2 / 12.8(7)$ & & $0.0162(5)$ \\
\hline Bred-2 & & 0 & 0 & $1 / 2$ & $63.5 / 36.5(10)$ & & $0.0178(6)$ \\
\hline Bred-3 & & 0 & 0 & $1 / 2$ & $34.1 / 65.9(12)$ & & $0.0198(6)$ \\
\hline Bred-4 & & 0 & 0 & $1 / 2$ & $10.0 / 90.0(2)$ & & $0.0233(9)$ \\
\hline M3 & $8 h$ & & & & & & \\
\hline Bred-1 & & $0.22607(5)$ & $0.00159(15)$ & $0.23610(9)$ & $100 / 0$ & & $0.0071(2)$ \\
\hline Bred-2 & & $0.22503(7)$ & $0.0015(2)$ & $0.23962(14)$ & $100 / 0$ & & $0.0065(3)$ \\
\hline Bred-3 & & $0.22668(4)$ & $0.00091(11)$ & $0.23227(7)$ & $93.1 / 6.9(6)$ & & $0.0082(3)$ \\
\hline Bred-4 & & $0.22653(5)$ & $0.00120(15)$ & $0.23367(9)$ & 83.9/16.1(8) & & $0.0092(5)$ \\
\hline M4 & $8 h$ & & & & & & \\
\hline Bred-1 & & $0.41192(4)$ & $0.15621(11)$ & $0.25053(6)$ & $92.0 / 8.0(4)$ & & $0.0091(2)$ \\
\hline Bred-2 & & $0.41237(4)$ & $0.15718(13)$ & $0.25081(8)$ & $73.1 / 26.9(6)$ & & $0.0090(3)$ \\
\hline Bred-3 & & $0.41272(4)$ & $0.15756(10)$ & $0.25082(7)$ & $56.0 / 44.0(6)$ & & $0.0075(2)$ \\
\hline Bred-4 & & $0.41311(5)$ & $0.15758(14)$ & $0.25047(13)$ & $37.5 / 62.5(9)$ & & $0.0072(3)$ \\
\hline M5 & $4 g$ & & & & & & \\
\hline Bred-1 & & $0.17130(5)$ & $0.33034(13)$ & 0 & $78.0 / 22.0(5)$ & & $0.0097(3)$ \\
\hline Bred-2 & & $0.17070(5)$ & $0.32958(14)$ & 0 & $51.1 / 48.9(8)$ & & $0.0105(3)$ \\
\hline Bred-3 & & $0.17029(5)$ & $0.33042(13)$ & 0 & $35.9 / 64.1(8)$ & & $0.0086(3)$ \\
\hline Bred-4 & & $0.17001(10)$ & $0.3307(2)$ & 0 & $20.1 / 79.9(15)$ & & $0.0100(6)$ \\
\hline M6 & $4 g$ & & & & & & \\
\hline Bred-1 & & $0.16544(6)$ & $0.30193(18)$ & $1 / 2$ & $95.8 / 4.2(5)$ & & $0.0131(4)$ \\
\hline Bred-2 & & $0.16593(6)$ & $0.3065(2)$ & $1 / 2$ & $79.2 / 20.8(8)$ & & $0.0144(5)$ \\
\hline Bred-3 & & $0.16646(7)$ & $0.31188(18)$ & $1 / 2$ & $58.4 / 41.6(8)$ & & $0.0141(4)$ \\
\hline Bred-4 & & $0.16671(11)$ & $0.3190(3)$ & $1 / 2$ & $35.0 / 65.0(14)$ & & $0.0140(7)$ \\
\hline M7 & $2 d$ & & & & & & \\
\hline Bred-1 & & $1 / 2$ & 0 & 0 & & $97.9 / 2.1(2)$ & $0.0069(8)$ \\
\hline Bred-2 & & $1 / 2$ & 0 & 0 & & $93.0 / 7.0(3)$ & $0.0055(11)$ \\
\hline Bred-3 & & $1 / 2$ & 0 & 0 & & $89.0 / 11.0(3)$ & $0.0065(11)$ \\
\hline Bred-4 & & $1 / 2$ & 0 & 0 & & $83.9 / 16.1(8)$ & $0.0063(19)$ \\
\hline M8 & $2 c$ & & & & & & \\
\hline Bred-1 & & $1 / 2$ & 0 & $1 / 2$ & & $92.1 / 7.9(2)$ & $0.0075(8)$ \\
\hline Bred-2 & & $1 / 2$ & 0 & $1 / 2$ & & $97.0 / 3.0(3)$ & $0.0073(11)$ \\
\hline Bred-3 & & $1 / 2$ & 0 & $1 / 2$ & & $90.0 / 10.0(3)$ & $0.0057(11)$ \\
\hline Bred-4 & & $1 / 2$ & 0 & $1 / 2$ & & $94.0 / 6.0(4)$ & $0.0030(19)$ \\
\hline Si1 & $8 h$ & & & & & & \\
\hline Bred-1 & & $0.08016(5)$ & $0.21907(16)$ & $0.74816(9)$ & & & $0.0061(3)$ \\
\hline Bred-2 & & $0.08035(7)$ & $0.2202(2)$ & $0.74909(14)$ & & & $0.0065(4)$ \\
\hline Bred-3 & & $0.08059(7)$ & $0.2213(2)$ & $0.74970(15)$ & & & $0.0057(4)$ \\
\hline Bred-4 & & $0.08070(12)$ & $0.2215(3)$ & $0.7511(3)$ & & & $0.0066(7)$ \\
\hline $\mathrm{Si} 2$ & $4 g$ & & & & & & \\
\hline Bred-1 & & $0.16622(7)$ & $0.7639(2)$ & 0 & & & $0.0058(4)$ \\
\hline Bred-2 & & $0.16697(9)$ & $0.7641(3)$ & 0 & & & $0.0065(6)$ \\
\hline Bred-3 & & $0.16702(12)$ & $0.7666(3)$ & 0 & & & $0.0059(6)$ \\
\hline Bred-4 & & $0.1660(2)$ & $0.7697(6)$ & 0 & & & $0.0093(11)$ \\
\hline
\end{tabular}


Table 2 (continued)

\begin{tabular}{|c|c|c|c|c|c|c|c|}
\hline \multicolumn{2}{|c|}{ Position, WS } & \multirow[t]{2}{*}{$\mathbf{x}$} & \multirow[t]{2}{*}{$\mathrm{y}$} & \multirow[t]{2}{*}{$\mathbf{z}$} & \multirow[t]{2}{*}{$\mathrm{Ca} / \mathrm{Sr}[\%]$} & \multirow[t]{2}{*}{$\mathrm{Mg} / \mathrm{Ca}[\%]$} & \multirow[t]{2}{*}{$\mathrm{U}(\mathrm{eq})\left[\AA^{2}\right]$} \\
\hline$\overline{\mathrm{Si} 3}$ & $4 g$ & & & & & & \\
\hline Bred-1 & & $0.33768(7)$ & $0.2812(2)$ & 0 & & & $0.0054(4)$ \\
\hline Bred-2 & & $0.33747(9)$ & $0.2813(3)$ & 0 & & & $0.0064(6)$ \\
\hline Bred-3 & & $0.33731(12)$ & $0.2821(3)$ & 0 & & & $0.0056(6)$ \\
\hline Bred-4 & & $0.3366(2)$ & $0.2831(6)$ & 0 & & & $0.0096(13)$ \\
\hline $\mathrm{O} 1$ & $8 h$ & & & & & & \\
\hline Bred-1 & & $0.02600(14)$ & $0.2827(4)$ & $0.6376(2)$ & & & $0.0151(8)$ \\
\hline Bred-2 & & $0.0278(2)$ & $0.2853(6)$ & $0.6370(4)$ & & & $0.0181(14)$ \\
\hline Bred-3 & & $0.0300(2)$ & $0.2882(7)$ & $0.6368(4)$ & & & $0.0193(14)$ \\
\hline Bred-4 & & $0.0331(4)$ & $0.2938(11)$ & $0.6360(7)$ & & & $0.021(3)$ \\
\hline $\mathrm{O} 2$ & $8 h$ & & & & & & \\
\hline Bred-1 & & $0.05253(16)$ & $0.3358(4)$ & $0.8699(3)$ & & & $0.0233(10)$ \\
\hline Bred-2 & & $0.0510(2)$ & $0.3338(6)$ & $0.8697(4)$ & & & $0.0247(16)$ \\
\hline Bred-3 & & $0.0492(2)$ & $0.3302(7)$ & $0.8701(4)$ & & & $0.0233(16)$ \\
\hline Bred-4 & & $0.0468(4)$ & $0.3262(12)$ & $0.8697(6)$ & & & $0.024(3)$ \\
\hline $\mathrm{O} 3$ & $8 h$ & & & & & & \\
\hline Bred-1 & & $0.15992(14)$ & $0.3126(4)$ & $0.7172(3)$ & & & $0.0147(8)$ \\
\hline Bred-2 & & $0.16008(18)$ & $0.3131(6)$ & $0.7205(4)$ & & & $0.0175(13)$ \\
\hline Bred-3 & & $0.1602(2)$ & $0.3126(6)$ & $0.7258(4)$ & & & $0.0173(14)$ \\
\hline Bred-4 & & $0.1594(3)$ & $0.3140(9)$ & $0.7330(8)$ & & & $0.027(2)$ \\
\hline $\mathrm{O} 4$ & $8 h$ & & & & & & \\
\hline Bred-1 & & $0.08873(15)$ & $0.9894(4)$ & $0.7781(2)$ & & & $0.0152(8)$ \\
\hline Bred-2 & & $0.0887(2)$ & $0.9905(6)$ & $0.7778(4)$ & & & $0.0197(14)$ \\
\hline Bred-3 & & $0.0881(2)$ & $0.9930(6)$ & $0.7754(4)$ & & & $0.0210(12)$ \\
\hline Bred-4 & & $0.0870(3)$ & $0.9944(9)$ & $0.7695(8)$ & & & $0.032(3)$ \\
\hline O5 & $8 h$ & & & & & & \\
\hline Bred-1 & & $0.20067(16)$ & $0.6588(4)$ & $0.8798(2)$ & & & $0.0211(9)$ \\
\hline Bred-2 & & $0.2016(2)$ & $0.6614(6)$ & $0.8797(4)$ & & & $0.0217(14)$ \\
\hline Bred-3 & & $0.2025(2)$ & $0.6672(7)$ & $0.8802(4)$ & & & $0.0237(16)$ \\
\hline Bred-4 & & $0.2038(4)$ & $0.6786(12)$ & $0.8804(6)$ & & & $0.013(3)$ \\
\hline O6 & $4 g$ & & & & & & \\
\hline Bred-1 & & $0.0815(2)$ & $0.7094(6)$ & 0 & & & $0.0203(14)$ \\
\hline Bred-2 & & $0.0828(2)$ & $0.7069(9)$ & 0 & & & $0.0190(19)$ \\
\hline Bred-3 & & $0.0837(3)$ & $0.7054(9)$ & 0 & & & $0.0177(17)$ \\
\hline Bred-4 & & $0.0859(6)$ & $0.6966(18)$ & 0 & & & $0.029(4)$ \\
\hline O7 & $4 g$ & & & & & & \\
\hline Bred-1 & & $0.1906(3)$ & $0.9912(6)$ & 0 & & & $0.0270(14)$ \\
\hline Bred-2 & & $0.1906(3)$ & $0.9891(9)$ & 0 & & & $0.035(2)$ \\
\hline Bred-3 & & $0.1880(6)$ & $0.9913(11)$ & 0 & & & $0.024(3)$ \\
\hline Bred-4 & & $0.1814(7)$ & $0.9968(16)$ & 0 & & & $0.025(5)$ \\
\hline $\mathrm{O} 8$ & $8 h$ & & & & & & \\
\hline Bred-1 & & $0.28888(13)$ & $0.2527(4)$ & $0.8780(2)$ & & & $0.0130(8)$ \\
\hline Bred-2 & & $0.28944(18$ & $0.2509(6)$ & $0.8780(4)$ & & & $0.0153(12)$ \\
\hline Bred-3 & & $0.2900(2)$ & $0.2470(6)$ & $0.8788(3)$ & & & $0.0177(14)$ \\
\hline Bred-4 & & $0.2902(4)$ & $0.2400(12)$ & $0.8792(6)$ & & & $0.025(2)$ \\
\hline O9 & $4 g$ & & & & & & \\
\hline Bred-1 & & $0.3980(2)$ & $0.1049(6)$ & 0 & & & $0.0165(11)$ \\
\hline Bred-2 & & $0.3985(2)$ & $0.1108(9)$ & 0 & & & $0.0227(19)$ \\
\hline Bred-3 & & $0.4001(3)$ & $0.1181(9)$ & 0 & & & $0.024(2)$ \\
\hline Bred-4 & & $0.4030(6)$ & $0.1302(18)$ & 0 & & & $0.030(4)$ \\
\hline
\end{tabular}


Table 2 (continued)

\begin{tabular}{lllllll}
\hline Position, WS & $\mathbf{x}$ & $\mathbf{y}$ & $\mathbf{z}$ & $\mathbf{C a} / \mathbf{S r}[\%]$ & $\mathbf{M g} / \mathbf{C a}[\%]$ & $\mathbf{U}(\mathbf{e q})\left[\AA^{2}\right]$ \\
\hline O10 & $4 g$ & & & & \\
Bred-1 & $0.3751(2)$ & $0.4940(6)$ & 0 & & $0.0125(11)$ \\
Bred-2 & $0.3733(3)$ & $0.4944(8)$ & 0 & & $0.0197(19)$ \\
Bred-3 & $0.3708(4)$ & $0.4971(9)$ & 0 & & $0.0247(19)$ \\
Bred-4 & $0.3678(6)$ & $0.4994(16)$ & 0 & & $0.032(4)$ \\
\hline
\end{tabular}

For those positions, for which the site-population refinements indicated the presence of one cation species only (within three standard uncertainties), the corresponding site populations are given as 0 and $100 \%$, respectively. The equivalent isotropic displacement parameter $\mathrm{U}(\mathrm{eq})$ is defined as one third of the trace of the orthogonalized $U_{\mathrm{ij}}$ tensor

the individual lattice parameters $a, b$ and $c$ (see Fig. 7a to c), which are enlarged by about $1.89,1.90$ and $1.11 \%$, respectively. This indicates that the $a$ and $b$ directions (showing almost identical change rates) are more affected by the strontium incorporation when compared with $c$. Including the literature data for a natural bredigite having a composition close to the pure calcium end-member (Kahlenberg et al. 2019), the evolution of the unit-cell volume and the individual lattice parameters as a function of the $\mathrm{Sr} /(\mathrm{Sr}+\mathrm{Ca})$ atomic ratio $\mathrm{X}$ can be described by the following linear expressions

$\mathrm{V}\left(\AA^{3}\right)=1349(3)+146(9) \cdot \mathrm{X} \quad \mathrm{R}^{2}=0.989$

$a(\AA)=18.36(1)+0.74(5) \cdot \mathrm{X} \mathrm{R}^{2}=0.988$

$b(\AA)=6.746(3)+0.29(1) \cdot \mathrm{X} \mathrm{R}^{2}=0.995$

$c(\AA)=10.89(1)+0.22(3) \cdot \mathrm{X} \mathrm{R}^{2}=0.940$

where $\mathrm{R}^{2}$ is the coefficient of determination.

The octahedrally coordinated M7 and M8 sites in the centers of the pinwheel-like moieties are $\mathrm{Mg}$-dominated. However, site-population refinements indicate the presence of small but nevertheless significant amounts of $\mathrm{Ca}^{2+}$-cations on these positions as well. Concerning the uptake of calcium atoms both sites exhibit an unlike behavior. While the Ca-Mg distributions on the M8-position do not allow to discern a clear trend as a function of the bulk composition, the M7 site incorporates increasing amounts of calcium atoms with increasing overall $\mathrm{Sr} /(\mathrm{Sr}+\mathrm{Ca})$ atomic ratio of the crystals.

Strontium cation substitution in the solid-solution series is limited to the positions M1 to M6. However, these six crystallographically independent sites show different preferences for the incorporation of $\mathrm{Sr}^{2+}$ (see Fig. 8). The primary sink for $\mathrm{Sr}$ is M1. Even for the lowest $\mathrm{Sr} /(\mathrm{Sr}+\mathrm{Ca})$ atomic ratio of $\mathrm{X}=0.133$ more than $90 \%$ of the calcium cations have already been replaced. The corresponding values for the remaining sites are drastically lower for this Ca-richest composition. From $\mathrm{X}=0.409$ onwards, M1 can be eventually considered a pure strontium position. The $\mathrm{Sr}$-occupancies for the sites M2, M4, M5, and M6 start from comparatively low levels but increase almost linearly and finally reach values between 62 and 90\%. By contrast, the M3-position exhibits only minor Sr-concentrations which vary between $0 \%$ (for $X=0.133$ ) to $16 \%$ (for $X=0.559$ ).

The $\mathrm{Si}-\mathrm{O}$ bond distances as well as $\mathrm{O}-\mathrm{Si}-\mathrm{O}$ angles of the three crystallographically independent $\left[\mathrm{SiO}_{4}\right]$-tetrahedra are in the normal range for silicate compounds (Liebau 1985).
Table 3 Positions and Wyckoff-symbols (WS), atomic coordinates as well as site populations for the mixed positions in sample Bred-5 (space group Pbam)

\begin{tabular}{llllllll}
\hline Position, WS & $\mathbf{x}$ & $\mathrm{y}$ & $\mathbf{z}$ & $\mathbf{C a} / \mathbf{S r}[\%]$ & $\mathrm{Mg} / \mathrm{Ca}[\%]$ & $\mathrm{U}(\mathrm{eq})\left[\AA^{2}\right]$ \\
\hline M1 & $2 a$ & 0 & 0 & 0 & $4.9 / 95.1(12)$ & $0.0216(4)$ \\
$\mathrm{M} 2$ & $4 h$ & $0.2239(1)$ & $0.0018(1)$ & $1 / 2$ & $34.8 / 65.2(8)$ & $0.0145(4)$ \\
M3 & $4 h$ & $0.4136(1)$ & $0.1570(1)$ & $1 / 2$ & $24.5 / 75.5(9)$ & \\
M4 & $4 \mathrm{~g}$ & $0.1679(1)$ & $0.3271(1)$ & 0 & $16.6 / 83.4(9)$ & & $0.0077(3)$ \\
M5 & $2 c$ & $1 / 2$ & 0 & 0 & & $85 / 15(2)$ & $0.0122(2)$ \\
Si1 & $4 h$ & $0.0801(1)$ & $0.2217(2)$ & $1 / 2$ & & $0.0063(9)$ \\
Si2 & $4 g$ & $0.1646(1)$ & $0.7771(2)$ & 0 & & $0.0091(4)$ \\
O1 & $8 i$ & $0.0393(2)$ & $0.3094(5)$ & $0.2660(5)$ & & $0.0265(9)$ \\
O2 & $4 h$ & $0.1592(2)$ & $0.3161(6)$ & $1 / 2$ & & $0.0273(12)$ \\
O3 & $4 h$ & $0.0860(3)$ & $0.9954(7)$ & $1 / 2$ & & $0.0417(15)$ \\
O4 & $8 i$ & $0.2073(2)$ & $0.7097(6)$ & $0.7616(6)$ & & $0.0376(10)$ \\
O5 & $4 g$ & $0.0911(2)$ & $0.6636(8)$ & 0 & & $0.0422(16)$ \\
O6 & $4 g$ & $0.3458(7)$ & $0.4984(9)$ & 0 & & $0.025(4)$ \\
\hline
\end{tabular}

The equivalent isotropic displacement parameter $\mathrm{U}(\mathrm{eq})$ is defined as one third of the trace of the orthogonalized $\mathrm{U}_{\mathrm{ij}}$ tensor 


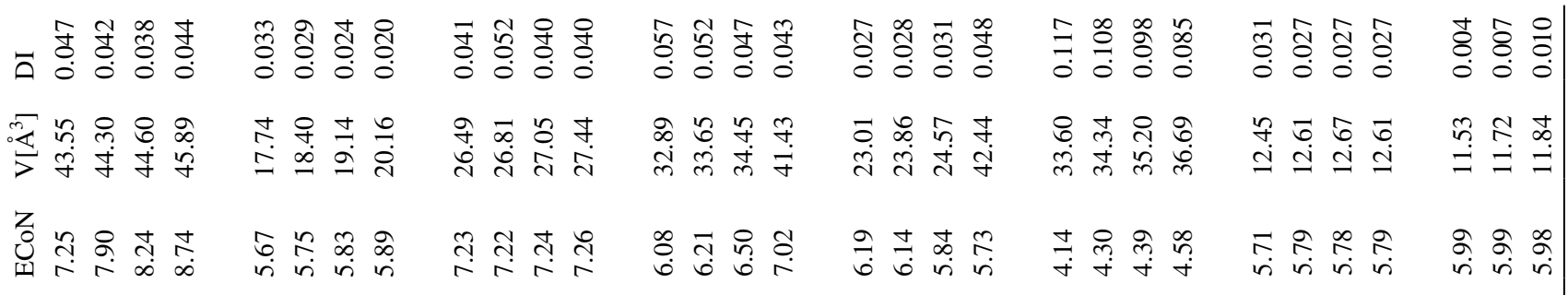

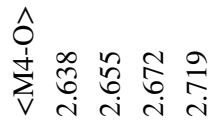

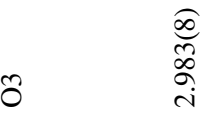

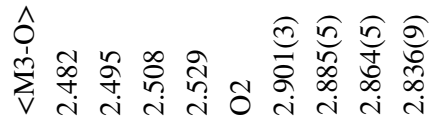

$\stackrel{\mathscr{s}}{\overline{0}}$

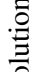

궁

宓

离

Еँّ

离

E

:

$\stackrel{Ð}{\Xi}$

$\stackrel{2}{\circ}$

$\exists$

$\stackrel{m}{9}$

离

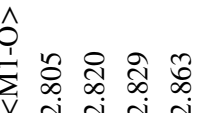

艾艾艾艾

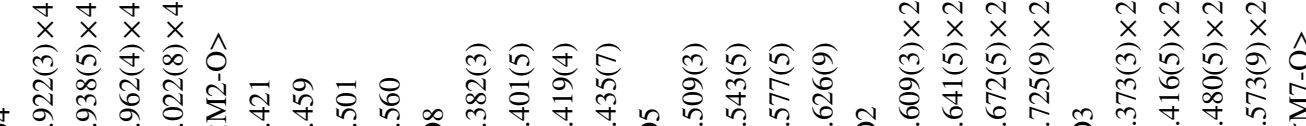

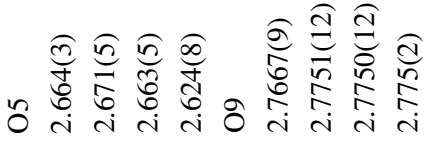

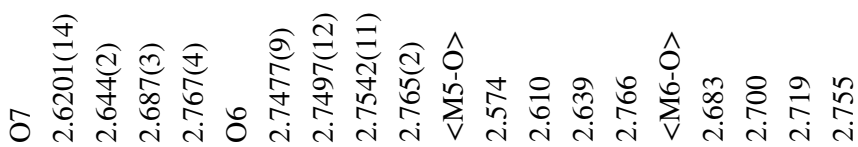

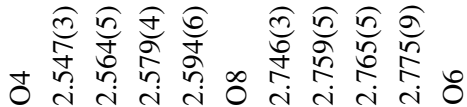

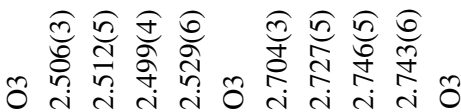

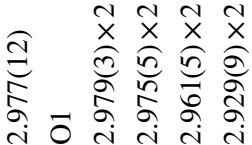

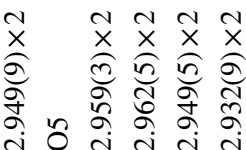

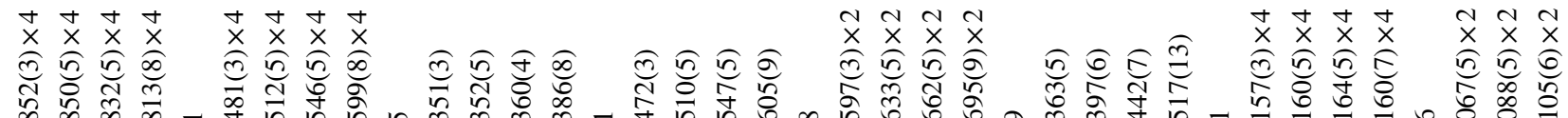

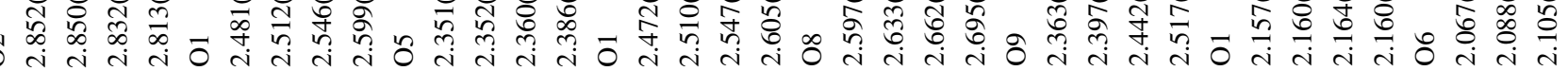

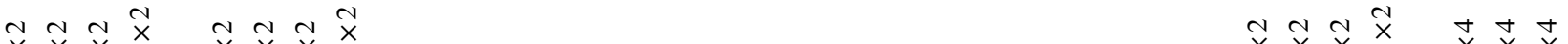

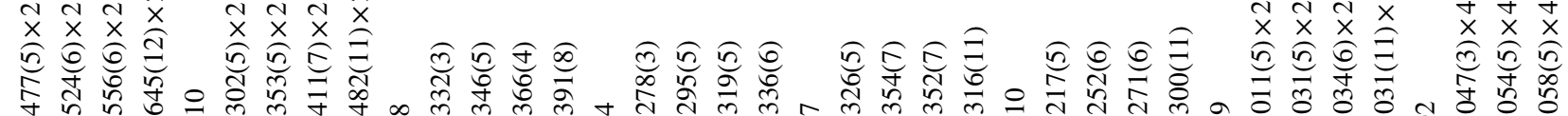

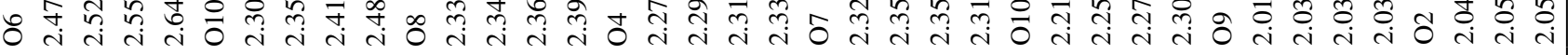

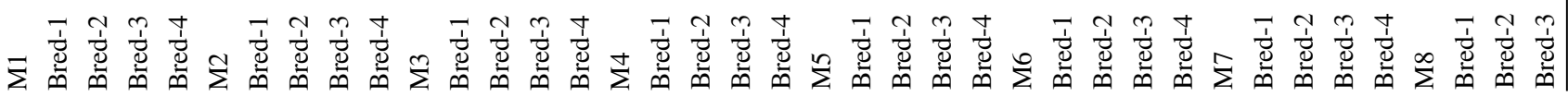




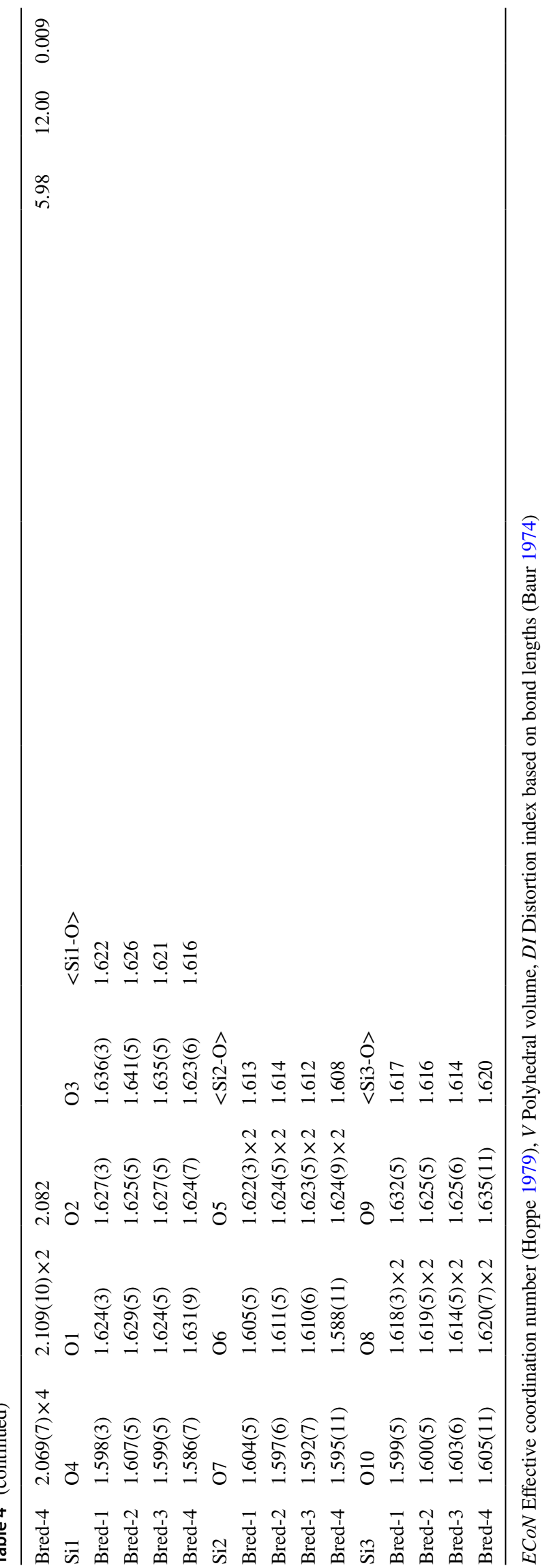

When comparing the $<\mathrm{Si}-\mathrm{O}>$-distances for the different members of the solid- solution series, no clear trends could be observed, i.e. the influence of the $\mathrm{Sr} / \mathrm{Sr}+\mathrm{Ca})$ atomic ratio on the geometry of the tetrahedra is insignificant. On the other hand, there are clear trends concerning the tilting angles of the $\left[\mathrm{SiO}_{4}\right]$-moieties. For example, the orientation of the tetrahedron around Sil residing on a general position can be specified by two angles $\Psi$ and $\Phi$. $\Psi$ can be defined as the angle between the base plane given by the oxygen atoms $\mathrm{O} 1, \mathrm{O} 2, \mathrm{O} 3$ and the [010]-direction, while $\Phi$ represents the angle between the edge O1-O2 and [001] (see Figs. 3a and 5a, respectively). $\Psi$ as well as $\Phi$ exhibit a continuous decrease with increasing $\mathrm{Sr} /(\mathrm{Sr}+\mathrm{Ca})$ atomic ratio. Actually, the values are reduced from 8.82 to $4.99^{\circ}$ (for $\Psi$ ) and 8.81 to $4.94^{\circ}$ (for $\Phi$ ), i.e. there is progress towards a less-tilted orientation of the $\left[\mathrm{SilO}_{4}\right]$-groups and we will come back to this point in the Discussion section. The tetrahedra centered by $\mathrm{Si} 2$ and $\mathrm{Si} 3$ are located on mirror planes perpendicular to [001]. Therefore, changes in orientation are more restricted and can be conveniently described with only one rotational parameter each: $\Delta$ and $\Lambda$. They represent the angles between the $b$-axis and the O6-O7 edge (for the $\left[\mathrm{Si}_{2} \mathrm{O}_{4}\right]$-tetrahedron) as well as the O9-O10 edge (for the $\left[\mathrm{Si}_{3} \mathrm{O}_{4}\right]$-unit), respectively (see Fig. 5a). Whereas $\Delta$ decreases from 46.48 to $40.87^{\circ}, \Lambda$ increases from 9.09 to $14.54^{\circ}$.

For the $\mathrm{Sr}$-free octahedra around $\mathrm{M} 7$ and $\mathrm{M} 8$, there is a gap between the $<$ M7-O $>$ - and the $<$ M8-O $>$-values which could be principally rationalized by the higher Ca-concentrations on M7, whose values increase from Bred-1 to Bred4. The average bond distances as well as the polyhedral volumes of the $\mathrm{M}^{7} \mathrm{O}_{6}$-octahedra, however, remain fairly constant within the series (see Table 4). For the M8 site, on the other hand, no clear trend concerning the $\mathrm{Ca}-\mathrm{Mg}$-incorporation could be detected, but nevertheless the $<\mathrm{M} 8-\mathrm{O}>$ distances and the volumes of the octahedra increase with increasing Sr-concentration of the mixed crystals. These findings point to the presence of an additional induced effect on the dimensions of the octahedra belonging to the pinwheels resulting from the $\mathrm{Sr}$-incorporation of the remaining six $\mathrm{M}$ sites. The analysis of the evolution of the corresponding $<\mathrm{M}-\mathrm{O}>$ values for these six positions shows an increase with rising overall $\mathrm{Sr} / \mathrm{Sr}+\mathrm{Ca})$ atomic ratios (see Table 4). Not surprisingly, the M1-position representing the "largest void" in the structure showing the largest polyhedral volume and the highest coordination number of 10 is especially prone to incorporation of strontium atoms. This finding confirms an earlier hypothesis presented by Moseley and Glasser (1982) who suggested a preferred uptake of larger alkaline-earth cations such as $\mathrm{Sr}$ or $\mathrm{Ba}$ on this site. As already mentioned, for the Sr-richest member of the solid-solution series an increase of the coordination number for two 
Table 5 Selected bond distances up to $3.11 \AA$ for the Pbam-type structure

\begin{tabular}{|c|c|c|c|c|c|c|c|c|c|c|}
\hline \multirow[t]{2}{*}{ M1 } & $\mathrm{O} 1$ & O5 & $<\mathrm{M} 1-\mathrm{O}>$ & & & & & ECoN & $\mathrm{V}\left[\AA^{3}\right]$ & DI \\
\hline & $2.709(3) \times 4$ & $2.901(6) \times 4$ & 2.807 & & & & & 7.61 & 30.45 & 0.035 \\
\hline \multirow[t]{2}{*}{ M2 } & $\mathrm{O} 2$ & $\mathrm{O} 2$ & $\mathrm{O} 4$ & $\mathrm{O} 2$ & $\mathrm{O} 3$ & O6 & $<\mathrm{M} 2-\mathrm{O}>$ & & & \\
\hline & $2.423(3) \times 2$ & $2.501(4)$ & $2.513(4) \times 2$ & $2.555(4)$ & $2.602(5)$ & $3.068(6) \times 2$ & 2.630 & 7.17 & 34.27 & 0.074 \\
\hline \multirow[t]{2}{*}{ M3 } & $\mathrm{O} 3$ & $\mathrm{O} 1$ & $\mathrm{O} 4$ & $\mathrm{O} 2$ & O5 & O1 & $<\mathrm{M} 3-\mathrm{O}>$ & & & \\
\hline & $2.350(5)$ & $2.712(3) \times 2$ & $2.728(3) \times 2$ & $2.738(4)$ & $2.773(3) \times 2$ & $2.881(4) \times 2$ & 2.728 & 7.39 & 41.47 & 0.030 \\
\hline \multirow[t]{2}{*}{ M4 } & O6 & O5 & $\mathrm{O} 2$ & $\mathrm{O} 4$ & O1 & $\mathrm{O} 4$ & $<\mathrm{M} 4-\mathrm{O}>$ & & & \\
\hline & $2.297(6)$ & $2.749(6)$ & $2.777(2) \times 2$ & $2.821(3) \times 2$ & $2.842(3) \times 2$ & $3.059(4) \times 2$ & 2.805 & 4.46 & 44.41 & 0.044 \\
\hline \multirow[t]{2}{*}{ M5 } & O5 & O1 & $<\mathrm{M} 5-\mathrm{O}>$ & & & & & & & \\
\hline & $2.061(4) \times 2$ & $2.115(3) \times 4$ & 2.097 & & & & & 5.97 & 12.25 & 0.012 \\
\hline \multirow[t]{2}{*}{ Sil } & $\mathrm{O} 3$ & $\mathrm{O} 1$ & $\mathrm{O} 2$ & $<$ Si1-O $>$ & & & & & & \\
\hline & $1.575(5)$ & $1.627(3) \times 2$ & $1.629(4)$ & 1.615 & & & & & & \\
\hline \multirow[t]{2}{*}{$\mathrm{Si} 2$} & O6 & O5 & $\mathrm{O} 4$ & $<\mathrm{Si} 2-\mathrm{O}>$ & & & & & & \\
\hline & $1.549(6)$ & $1.594(5)$ & $1.617(3) \times 2$ & 1.594 & & & & & & \\
\hline
\end{tabular}

ECoN Effective coordination number (Hoppe 1979), V Polyhedral volume, DI Distortion index based on bond lengths (Baur 1974)

of the $\mathrm{M}$ sites from 9 to 10 (for M4) and from 7 to 10 (for M5) has been observed. A more detailed analysis of the evolution of the coordination environments for those cations that do not exhibit any changes in their coordination spheres can be achieved by the calculation of their effective coordination number $(\mathrm{ECoN})$ as defined by Hoppe (1979) (see Table 4). The most pronounced changes have been observed for M1 (increase by about $20 \%$ ), while the values for M3 remain almost constant. The low ECoN-values for the M6 site ranging from 4.14 to 4.58 indicate that the formal nine-fold coordination is more adequately described as a $4+5$ coordination. Actually, this position also exhibits the most significant bond-lengths distortion index (see Table 4).

\section{Pbam structure}

The crystal structure of the Pbam polymorph is based on the same principal building blocks that have been identified in the Pnnm structure: chains of $\mathrm{MSi}_{6} \mathrm{O}_{24}$-clusters running along [001] (see Figs. 2b and 3b). However, for the Pbam case, adjacent pinwheels along the chains are equivalent by translation symmetry. Actually, the local symmetry of the pinwheels in both structure types are identical: $2 / m$. An important difference stems from the fact the bridging tetrahedra about Si1 in Pbam are located on mirror planes as well, whereas the corresponding groups in the Pnnm-structure are twisted and tilted away from the special positions which results in a loss of these mirror planes (see Fig. 2a and b). A more detailed analysis of the relative distortions between both modifications based on concepts of group-theory will be presented in the next section.
Concerning the geometry of the $\left[\mathrm{SiO}_{4}\right]$-tetrahedra it can be noted that the range of the individual $\mathrm{Si}-\mathrm{O}$ distances in the Pbam modification is larger, but that distortion parameters such as quadratic elongations $(\lambda)$ or bond angle variances $\left(\sigma^{2}\right)$ as defined by Robinson et al. (1971) are not that much influenced. While the values for $\mathrm{Si} 1$ and $\mathrm{Si} 2$ range from 1.001 to 1.003 (for $\lambda$ ) and 4.796 and 14.685 (for $\sigma^{2}$ ) the corresponding data for the three symmetrically independent tetrahedra in sample Bred-4 scatter between 1.001-1.005 and 4.634-22.395, respectively.

The most dramatic change with respect to $\mathrm{Sr} / \mathrm{Ca}$ occupancies can be observed for the M2 site corresponding to the position M3 in the Pnnm-structure. Actually, the Sr-content increases from 16\% (in sample Bred-4) to about $65 \%$ in the Pbam-phase. Furthermore, the number of next oxygen neighbors shows an increase for this position from eight to nine, as do the average bond distances (rise from 2.529 to $2.630 \AA$, see Table 5).

Finally, it has to be emphasized that Moore and Araki (1976) in their landmark paper on the genealogy of alkaline-earth orthosilicates already sketched a structural model of a bredigite aristotype having a Pbam arrangement (or $P m c b$ according to their preferred setting) which conforms closely with our experimentally determined crystal structure for $\mathrm{Ca}_{2.32} \mathrm{Sr}_{4.82} \mathrm{Mg}_{0.86}\left[\mathrm{SiO}_{4}\right]_{4}$. We are pleased that we were able to confirm the realization of this hypothetical structure whose derivation 45 years ago was based on purely geometrical considerations. 

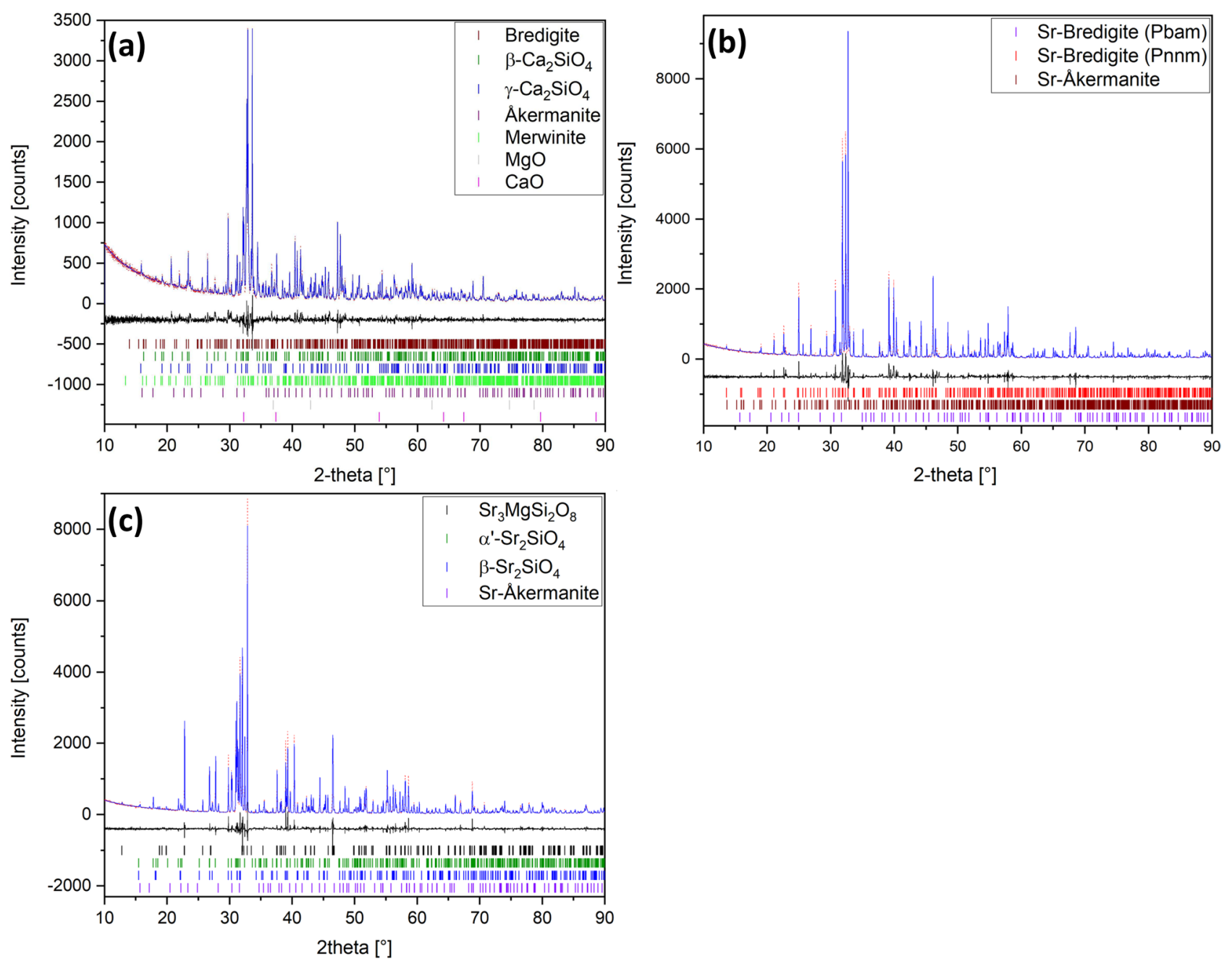

Fig. 1 Rietveld plots of the powder X-ray diffraction patterns of selected samples synthesized from solid-state reactions: (a) Bred-0, (b) Bred-5 and (c) Bred-7. Observed step intensities are presented by red dots. Calculated step intensities (solid blue line) have been mod-

eled based on a mixture of the crystalline phases listed in the insets. Tick marks for the Bragg peaks of each phase are given. The lower black line represents the difference curve between observed and calculated step intensities

\section{Discussion}

Diffraction experiments point to a klassengleiche phase transition of index 2 somewhere in the compositional range between $\mathrm{Sr} /(\mathrm{Sr}+\mathrm{Ca})=0.559$ and 0.675 . The space groups Pbam (high symmetry) and Pnnm (low symmetry) are in a group-subgroup relationship and the crystal structures have similar topological features. In summary, one can say that the atomic coordinates of the structure types are related by the following transformation $(\mathrm{P}, \mathrm{p})$ : $\mathbf{a}, \mathbf{b}, 2 \mathbf{c}(0,0,0)$.

A more detailed understanding of the phase transformation can be achieved by symmetry-mode analysis. In the course of this procedure implemented in the program AMPLIMODES (Orobengoa et al. 2009) the structural distortions present in the low-symmetry structure are

decomposed into contributions from different modes, whose symmetries are given by the irreducible representations (irreps) of the space group of the parent or highsymmetry phase.

Due to the maximal group-subgroup relationship, the onset of one primary mode could already explain the observed symmetry break directly. It corresponds to the irrep $Z_{2}^{+}$of space group Pbam associated with the point $\mathrm{Z}$ $(0,0,1 / 2)$ of the first Brillouin zone. Furthermore, the trivial fully symmetrical $\Gamma_{1}^{+}$distortion is also allowed that retains the symmetry of the Pbam-structure.

Using the crystallographic data for the boundary compositions with $\mathrm{Sr} /(\mathrm{Sr}+\mathrm{Ca})=0.559($ Pnnm $)$ and 0.675 (Pbam) , a reference structure was calculated in a first step representing the parent phase, but expressed in the low-symmetry space group (see supplementary Table S3). Notably, several 

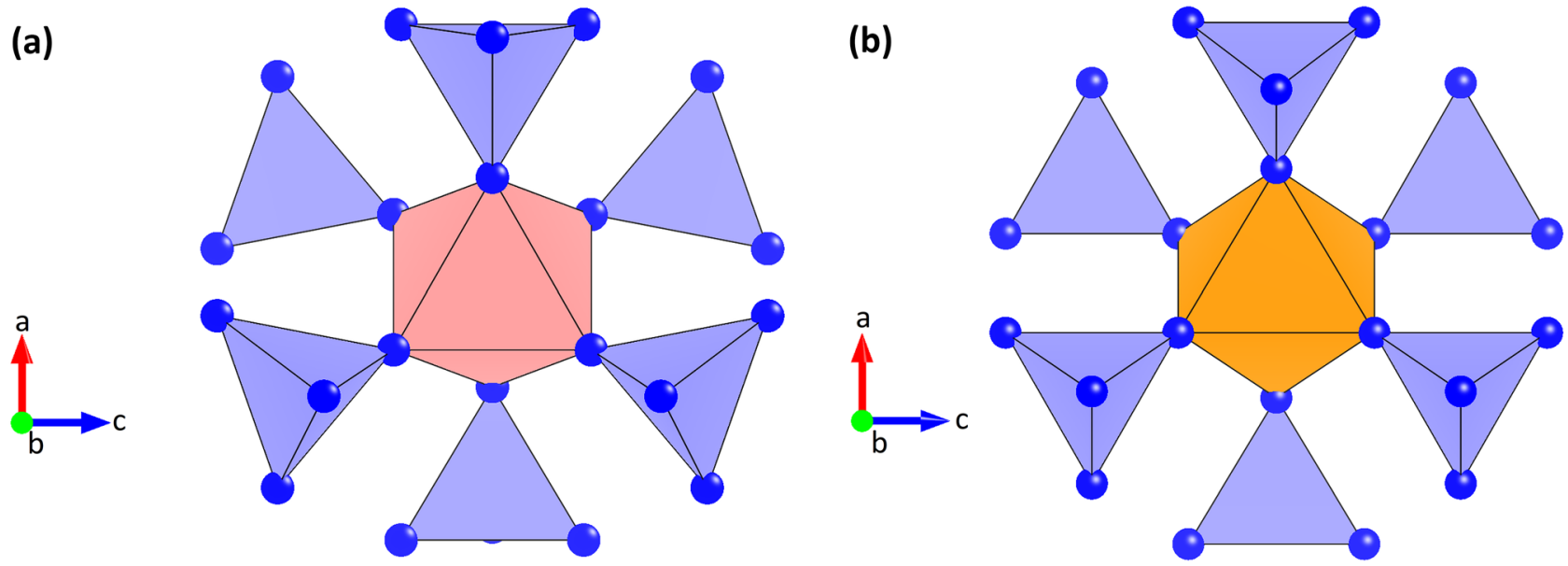

Fig. $2 \mathrm{MSi}_{6} \mathrm{O}_{24}$ polyhedral microensembles (PME) or pinwheel clusters in the (a) Pnnm and (b) Pbam structure-type. Blue spheres represent oxygen atoms. The six tetrahedra exhibit an $U D U D U D$ conformation of up $(U)$ and down $(D)$ pointing apices

Wyckoff orbits have split. Due to the splitting, the number of independent atoms in the asymmetric unit increases from 13 to 21 . The resulting displacement field obtained from the comparison of the reference structure with the low-symmetry Pnnm-phase is given in Table 6. The displacement vectors u for the atoms in the asymmetric unit of the reference structure listed in this table completely define the displacive distortions relating both structures. It is obvious, that the oxygen atoms are distinctly more affected by the phase transformation. Their absolute shifts vary between 0.162 and $0.509 \AA$. The silicon atoms and most of the M sites show considerably smaller displacements. An exception, however, is the M2 position which is shifted by about $0.188 \AA$. Actually, this site shows largest increase in Sr-occupancy due to the phase transition. The average displacement of all corresponding atom pairs in both structures has a value of $0.159 \AA$.

In the next step of mode analysis, the absolute amplitudes for the two individual components of the global distortions were calculated. The relevant values are $2.104 \AA$ (for $Z_{2}^{+}$) and $0.234 \AA$ (for $\Gamma_{1}^{+}$), i.e. the $Z_{2}^{+}$-mode is about ten times larger, indicating that the onset of this mode triggers the transition. However, for a complete understanding the
Fig. 3 Chain-like elements of linked pinwheels in the (a) Pnnm and (b) Pbam structuretype. The chains are running along [001]
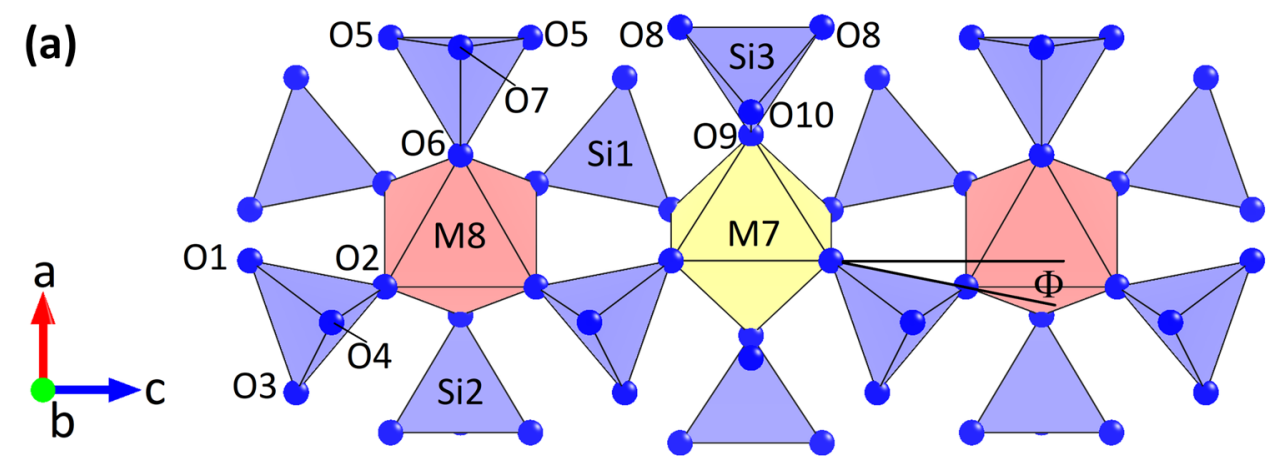

(b)
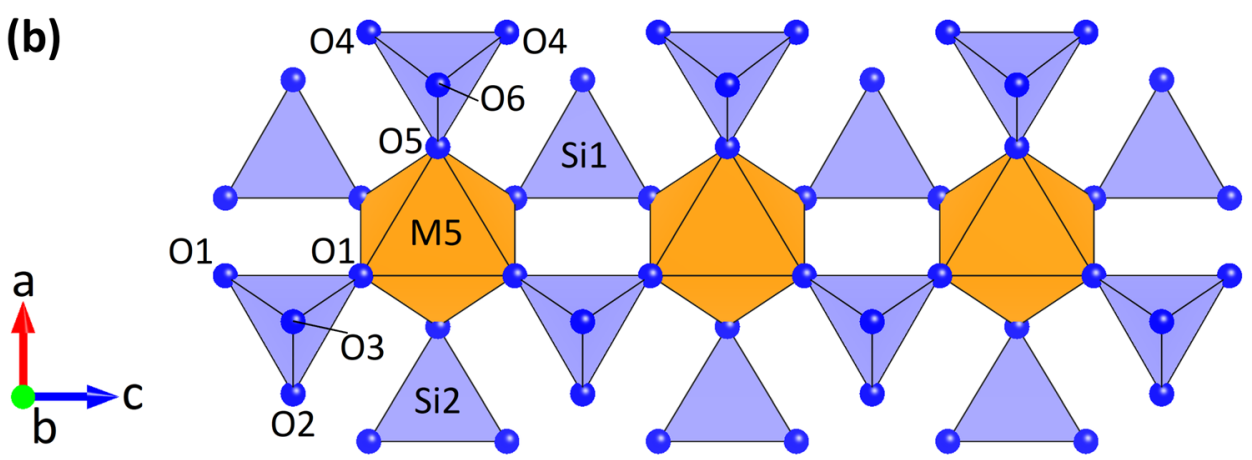
Fig. 4 Projections of the whole structures along [010]: (a) Pnnm- and (b) Pbam-structure type. Sr- and Ca cations are given by pink and green spheres. Bi-colored spheres indicate mixed $\mathrm{Sr}$-Ca positions. Occupancies refer to the values for samples Bred-1 and Bred-5, respectively
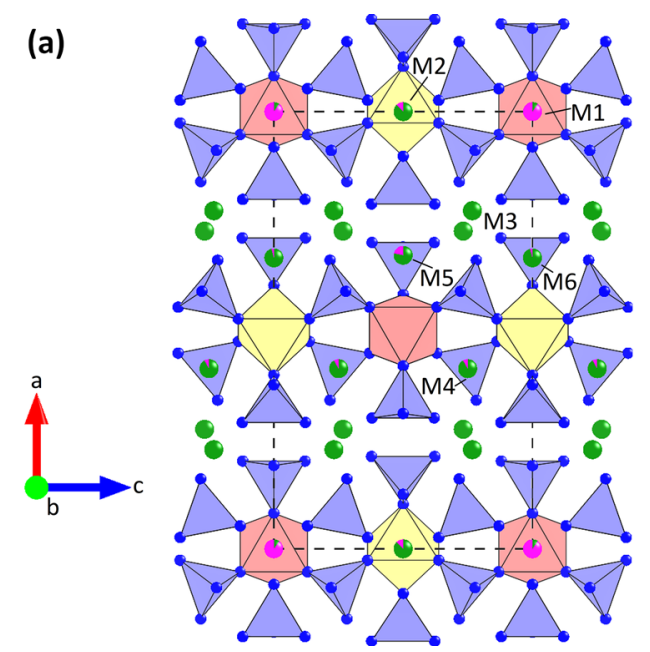

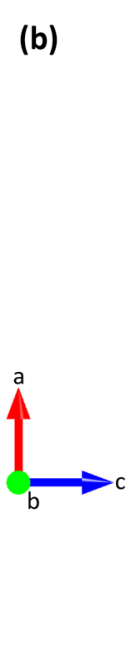

contributions of the trivial non-symmetry breaking $\Gamma_{1}^{+}$-mode have to be considered as well.

Finally, for each involved irrep the corresponding polarization vector was obtained. Supplementary Table S4 shows a crystallographic description of these normalized vectors. For the asymmetric unit of the reference structure the set of correlated atomic displacements (in relative units) is given for both irreps. The actual distortion of a specific mode can be easily obtained by multiplying the components of the polarization vector with the amplitudes mentioned above. For $Z_{2}^{+}$, for example, columns 5 to 7 have to multiplied with the corresponding amplitude of $2.104 \AA$. From inspection of Table $\mathrm{S} 4$ it is clear that neither $Z_{2}^{+}$nor $\Gamma_{1}^{+}$induce any displacement of the M1- or the M5-position. For the M2 site, for example, the displacement vectors related to $Z_{2}^{+}$are strictly parallel or anti-parallel to [001]. In order to obtain a concise graphical overview of the distortion fields, individual displacements of the most affected atoms (M2, O1-O6) calculated for the dominant $Z_{2}^{+}$representation only have been visualized using the program VESTA3 (see Fig. 9).

The aforementioned orientation angles $\Psi$ and $\Phi$ of the $\left[\mathrm{SiO}_{4}\right]$-tetrahedra could be used as order parameters for the characterization of the phase transformation: due to symmetry constraints their values are strictly zero in the Pbamphase, while they can deviate from $0^{\circ}$ in the Pnnm-phase. The evolution of $\Psi$ as a function of the $\mathrm{Sr} /(\mathrm{Sr}+\mathrm{Ca})$ atomic ratio, for example, is given in Fig. 10. In order to increase the number of data, we included the corresponding value for a natural bredigite sample with a composition close to the calcium end-member (Kahlenberg et al. 2019). A non-linear decrease of $\Psi$ can be recognized. In principle, the present Pbam - Pnnm phase transformation could be continuous
Fig. 5 Projections of the whole structures along [001]: (a) Pnnm- and (b) Pbam-structure type. Sr- and Ca cations are given by pink and green spheres. Bi-colored spheres indicate mixed $\mathrm{Sr}-\mathrm{Ca}$ positions. Occupancies refer to the values for the samples Bred-1 and Bred-5, respectively

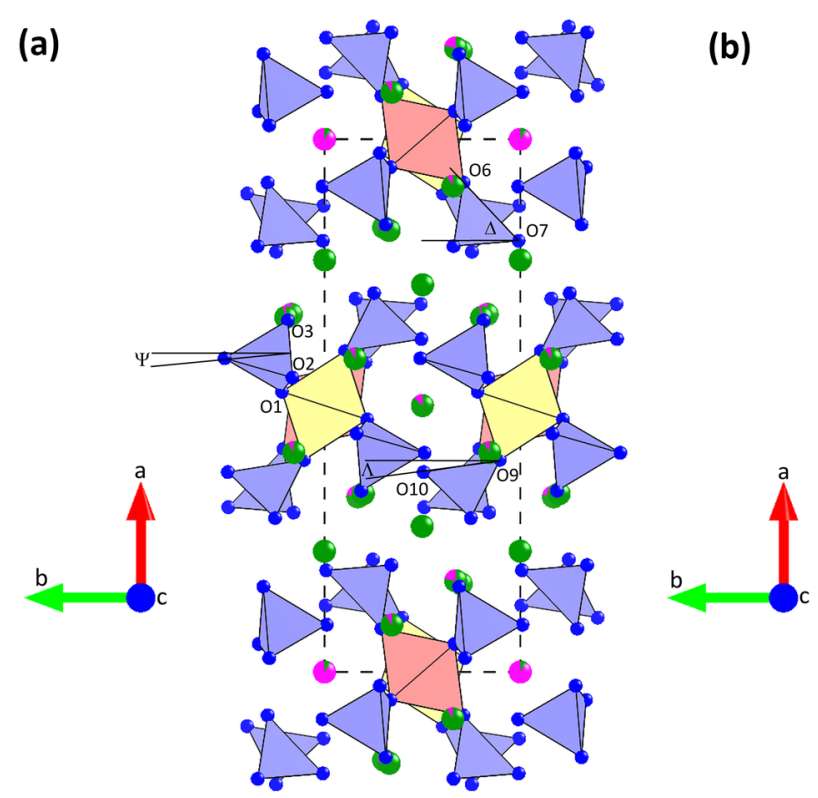




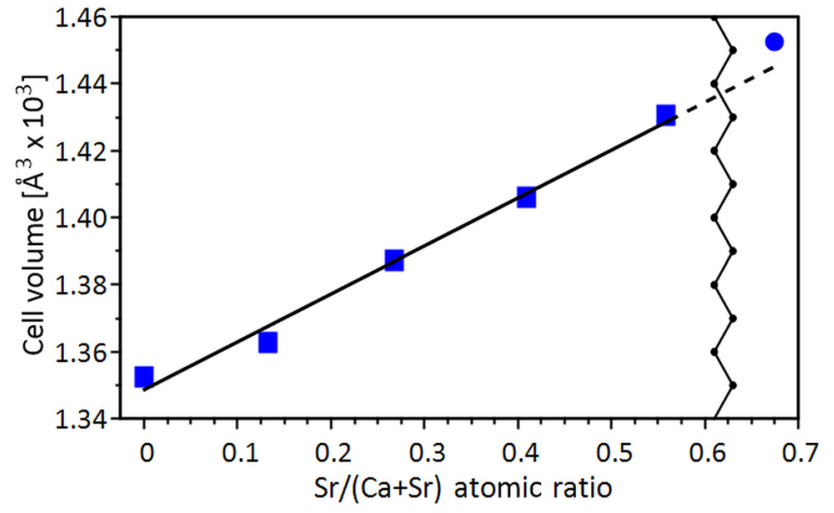

Fig. 6 Evolution of the unit-cell volumes of the samples from the runs Bred-1 to Bred-4 (squares) and Bred-5 (filled circle) as a function of the $\mathrm{Sr} /(\mathrm{Sr}+\mathrm{Ca})$ atomic ratio. The data point for $\mathrm{Sr} /$ $(\mathrm{Sr}+\mathrm{Ca})=0$ has been taken from Kahlenberg et al. (2019)

within the framework of Landau as well as renormalization theory (Stokes and Hatch 1988). However, the limited number of data points in the vicinity of the transition do not allow a final conclusion if the transition is really combined with a continuous evolution of the order parameter. Under the assumptions (i) that the transformation is of second order and that the critical composition $\mathrm{X}_{\mathrm{c}}$ corresponds to the midpoint between the two boundary compositions (this is $\left.X_{c}=0.617\right)$, the order parameter $\Psi$ has been fitted using the relation $\Psi \sim\left(\mathrm{X}_{\mathrm{c}}-\mathrm{X}\right)^{\beta}$. The derived critical exponent $\beta$ has a value of $0.24(2)$. The resulting curve is shown in Fig. 10 and should be regarded as a guide to the eye.

\section{Conclusions}

Structural information on the $\mathrm{Ca}-\mathrm{Sr}$ substitution in natural silicates is limited. This is related to the fact that strontium is generally present in minerals only as a minor or trace element. While there are some data in the literature concerning the Sr-content of natural feldspars (Lagache and Dujon 1987 and references cited therein) only a small number of other silicate minerals have been structurally characterized, where larger amounts of calcium have been replaced with strontium atoms. Examples include slawsonite (the $\mathrm{Sr}$-analog of paracelsian, Griffen et al. 1977), piemontite (Catti et al. 1988) or melilite (Bindi et al. 2001). More systematic investigations on $\mathrm{Ca}-\mathrm{Sr}$ substitutions among silicates are restricted to a few synthetic samples and involve $\alpha-\left(\mathrm{Ca}_{1-\mathrm{x}} \mathrm{Sr}_{\mathrm{x}}\right) \mathrm{SiO}_{3}$ (Ohsato et al. 2017), $\mathrm{Ca}_{2-\mathrm{x}} \mathrm{Sr}_{\mathrm{x}} \mathrm{SiO}_{4}$ (Catti et al. 1984; Chen
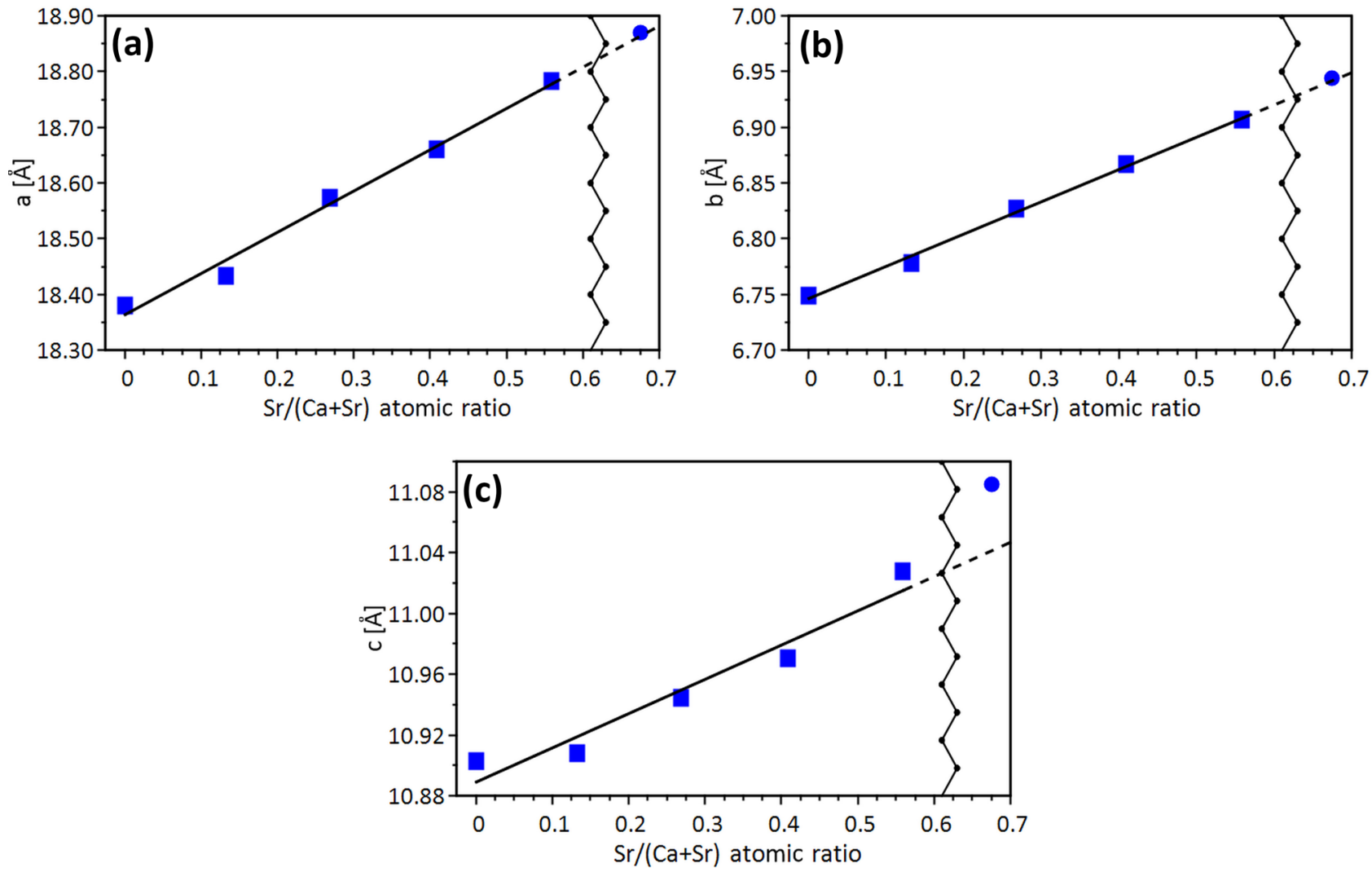

Fig. 7 Evolution of the lattice parameters of the samples from the runs Bred-1 to Bred-4 (squares) and Bred-5 (filled circle) as a function of the $\mathrm{Sr} /(\mathrm{Sr}+\mathrm{Ca})$ atomic ratio. The data point for $\mathrm{Sr} /(\mathrm{Sr}+\mathrm{Ca})=0$ has been taken from Kahlenberg et al. (2019) 


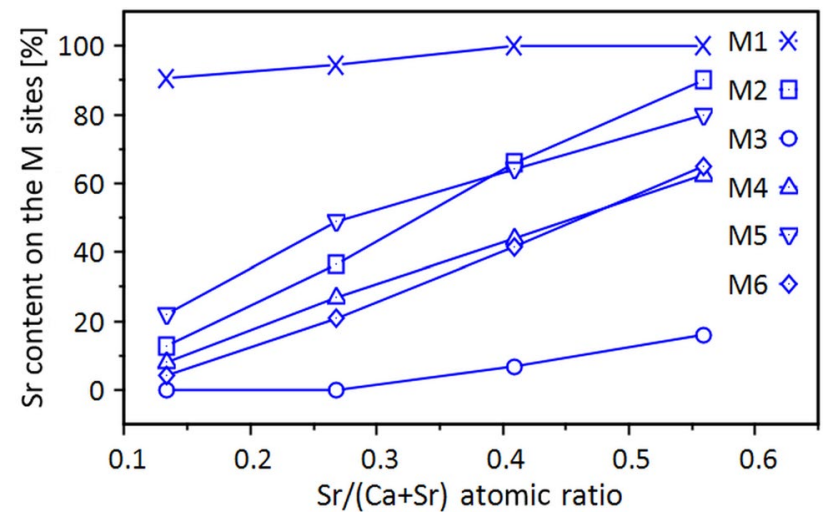

Fig. 8 Variation of the Sr-concentrations for the six M sites outside the pinwheel-like building units as a function of the $\mathrm{Sr} /(\mathrm{Sr}+\mathrm{Ca})$ atomic ratio

et al. 2015), Ca-Sr-diopside (Benna et al. 1987) or Ca-Srzoisite/clinozoisite (Dörsam et al. 2007). Similar to the present case, for the $\mathrm{Ca}_{2-\mathrm{x}} \mathrm{Sr}_{\mathrm{x}} \mathrm{SiO}_{4}$ solid-solution series the existence of a compositional-dependent phase transition from the so-called $\beta$ - to the $\alpha$ '-modification has been reported (Chen et al. 2015).

Table 6 Displacement field for the low-symmetry Pnnm-phase

\begin{tabular}{|c|c|c|c|c|}
\hline \multirow[t]{2}{*}{ Atom } & \multicolumn{4}{|c|}{ Atomic displacements } \\
\hline & $\mathrm{u}_{\mathrm{x}}$ & $\mathrm{u}_{\mathrm{y}}$ & $\mathrm{u}_{\mathrm{z}}$ & $|\mathbf{u}|$ \\
\hline M1 (M1) & 0.0000 & 0.0000 & 0.0000 & 0.000 \\
\hline M1_2 (M2) & 0.0000 & 0.0000 & 0.0000 & 0.000 \\
\hline M2 (M3) & 0.0026 & -0.0006 & -0.0163 & 0.188 \\
\hline M3 (M4) & -0.0005 & 0.0006 & 0.0005 & 0.011 \\
\hline M4 (M5) & 0.0021 & 0.0036 & 0.0000 & 0.047 \\
\hline M4_2 (M6) & 0.0012 & -0.0081 & 0.0000 & 0.061 \\
\hline M5 (M7) & 0.0000 & 0.0000 & 0.0000 & 0.000 \\
\hline M5_2 (M8) & 0.0000 & 0.0000 & 0.0000 & 0.000 \\
\hline Si1 (Si1) & 0.0006 & -0.0002 & -0.0011 & 0.017 \\
\hline $\mathrm{Si} 2(\mathrm{Si} 2)$ & 0.0014 & -0.0074 & 0.0000 & 0.058 \\
\hline $\mathrm{Si} 2 \_2(\mathrm{Si} 3)$ & 0.0012 & 0.0060 & 0.0000 & 0.047 \\
\hline $\mathrm{O} 1(\mathrm{O} 2)$ & 0.0075 & 0.0168 & -0.0027 & 0.185 \\
\hline O1_2(O1) & 0.0062 & -0.0156 & -0.0030 & 0.162 \\
\hline $\mathrm{O} 2(\mathrm{O} 3)$ & 0.0002 & -0.0021 & 0.0170 & 0.189 \\
\hline $\mathrm{O} 3(\mathrm{O} 4)$ & 0.0010 & -0.0010 & -0.0195 & 0.217 \\
\hline O4 (O8) & 0.0025 & 0.0303 & -0.0016 & 0.216 \\
\hline O4_2(O5) & 0.0035 & -0.0311 & 0.0004 & 0.226 \\
\hline O5 (O6) & -0.0052 & 0.0330 & 0.0000 & 0.249 \\
\hline O5_2(O9) & -0.0059 & -0.0334 & 0.0000 & 0.257 \\
\hline O6 (O10) & 0.0220 & 0.0010 & 0.0000 & 0.411 \\
\hline O6_2(O7) & 0.0272 & -0.0016 & 0.0000 & 0.509 \\
\hline
\end{tabular}

$\mathrm{u}_{\mathrm{x}}, \mathrm{u}_{\mathrm{y}}$ and $\mathrm{u}_{\mathrm{z}}$ are given in relative units. $|\mathbf{u}|$ is the absolute displacement in $\AA$. Wyckoff-splittings are indicated using underscore signs, e.g. M1_2. Labels in parentheses refer to the nomenclature of the positions used in the low-symmetry phase

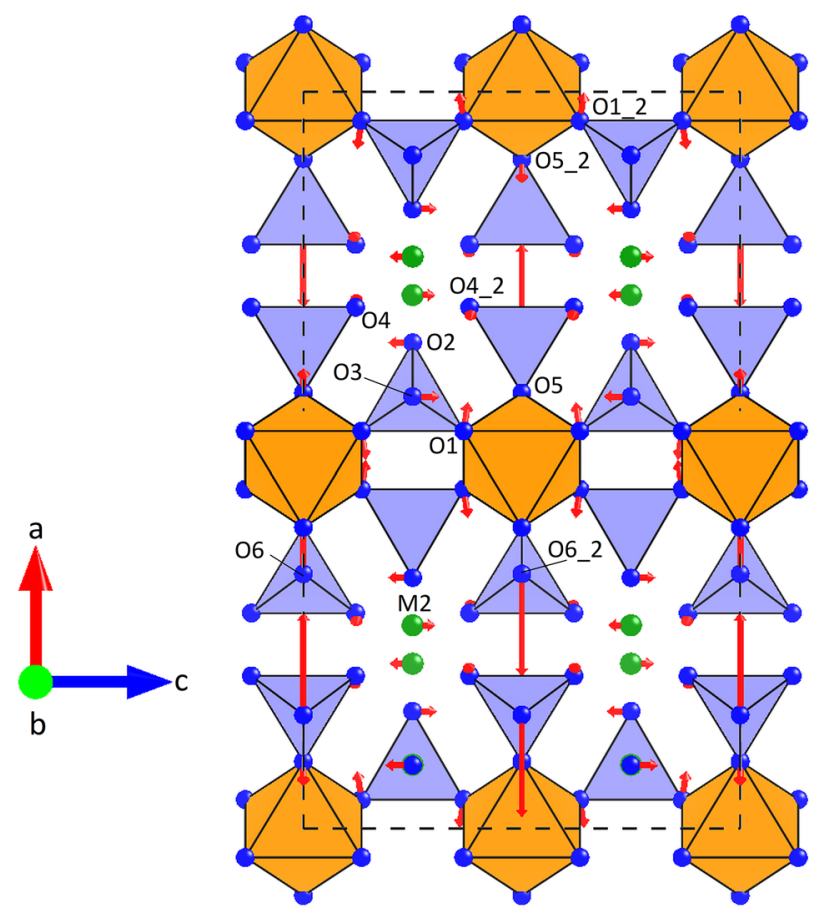

Fig. 9 Displacement field induced by the irrep $Z_{2}^{+}$on the most affected atoms (M2 site, oxygen anions) of the reference structure. Labeling has been performed in accordance with Table 6. For sake of better visibility, the magnitudes of the individual shift vectors (red) have been scaled with a common factor

The present study focused on a better understanding of the fundamental structural impacts resulting from the $\mathrm{Sr}-\mathrm{Ca}$ substitution into the bredigite structure type. However, more comprehensive information on this specific solid-solution series could be also of importance for the improvement of bredigite's physical and biological properties in bioactive ceramics. Enhanced osteoporotic bone regeneration, for example, has been described for other alkaline earth silicates

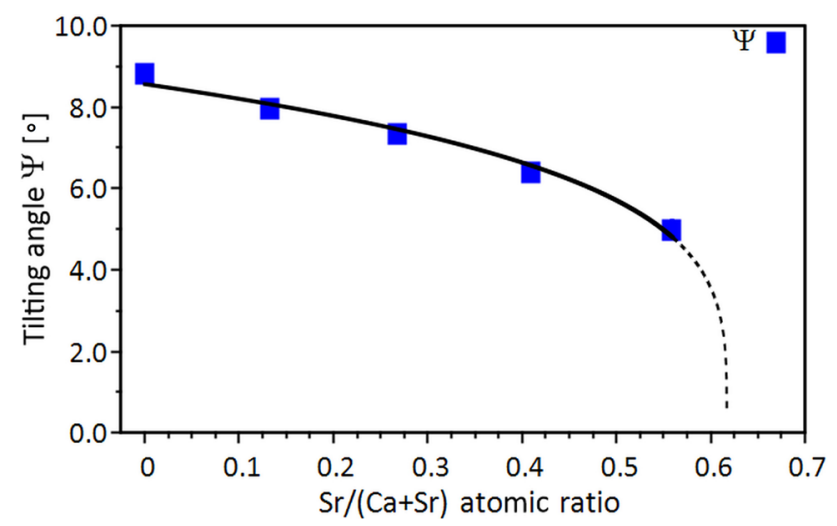

Fig. 10 Evolution of the tilting angle $\Psi$ of the $\left[\mathrm{SilO}_{4}\right]$-tetrahedron as a function of the composition of the solid-solution series. The curve is a guide to the eye 
such as $\alpha$ - and $\beta-\mathrm{CaSiO}_{3}$ after doping with strontium (No et al. 2017) and the same effect may be observable for $\mathrm{Sr}$ substituted bredigite as well.

The existence of Ba-substituted bredigite-type mixedcrystals has been already suggested by Moore and Araki (1976). Actually, Moseley and Glasser (1982) claimed successful synthesis experiments on $\mathrm{Ca}_{6.5} \mathrm{Ba}_{0.5}\left[\mathrm{SiO}_{4}\right]_{4}$ and $\mathrm{Ca}_{6} \mathrm{Ba}\left[\mathrm{SiO}_{4}\right]_{4}$, respectively. While the powder pattern of the first compound could be satisfactorily indexed with a standard bredigite-type cell, the match between the observed diffractogram and the peak positions suggested by the orthorhombic primitive metric for the second composition was markedly less convincing. Therefore, Moseley and Glasser eventually proposed an orthorhombic $B$-centered cell with a doubled $b$ lattice parameter for $\mathrm{Ca}_{6} \mathrm{Ba}\left[\mathrm{SiO}_{4}\right]_{4}$ (when referred to our preferred setting of the unit cell). Full details and an indexed powder pattern, though announced by the authors, have never been published. Attempts aiming on the growth of single-crystals at the compositions of the $\mathrm{Ba}-\mathrm{Ca}$ solid-solution series combined with structural investigations could prove a fruitful investigation shedding more light on bredigite's structural response to the replacement of calcium with barium.

Finally, we would like to mention that $\mathrm{Sr}_{3} \mathrm{Mg}\left[\mathrm{SiO}_{4}\right]_{2}-$ one of the phases that occurred in the Bred-7 sample-is also based on pinwheel-like clusters and structurally related to merwinite (Yonesaki 2015). For this compound, cation substitutions among the larger alkaline-earth ions also triggered compositionally dependent phase transitions. Along the $\mathrm{Ba}_{\mathrm{x}} \mathrm{Sr}_{3-\mathrm{x}} \mathrm{Mg}\left[\mathrm{SiO}_{4}\right]_{2}$ solid-solution, for example, three different but closely related structures could be distinguished. Similar to the present case, the observed symmetry changes have been attributed to tilts of the silicate tetrahedra caused by size mismatches of the alkaline-earth ions in the interstitial positions between the pinwheel clusters (Yonesaki 2015).

Supplementary Information The online version contains supplementary material available at https://doi.org/10.1007/s00710-021-00771-x.

Acknowledgements The authors thank Herta Silvia Effenberger and Irina Galuskina for their recommendations and comments which improved the manuscript.

Funding Open access funding provided by University of Innsbruck and Medical University of Innsbruck.

Open Access This article is licensed under a Creative Commons Attribution 4.0 International License, which permits use, sharing, adaptation, distribution and reproduction in any medium or format, as long as you give appropriate credit to the original author(s) and the source, provide a link to the Creative Commons licence, and indicate if changes were made. The images or other third party material in this article are included in the article's Creative Commons licence, unless indicated otherwise in a credit line to the material. If material is not included in the article's Creative Commons licence and your intended use is not permitted by statutory regulation or exceeds the permitted use, you will need to obtain permission directly from the copyright holder. To view a copy of this licence, visit http://creativecommons.org/licenses/by/4.0/.

\section{References}

Baur WH (1974) The geometry of polyhedral distortions. Predictive relationships for the phosphate group. Acta Crystallogr B 30:1195-1215

Benna P, Chiari G, Bruno E (1987) Structural modifications in clinopyroxene solid solutions: the $\mathrm{Ca}-\mathrm{Mg}$ and $\mathrm{Ca}-\mathrm{Sr}$ substitutions in the diopside structure. Mineral Petrol 36:71-84

Bindi L, Bonazzi P, Fitton JG (2001) Crystal chemistry of strontian soda melilite from nephelinite. Eur J Mineral 13:121-125

Blaß G, Kruijen F (2014) Die Neuigkeiten aus der Vulkaneifel (2/14). Mineralien-Welt 25:62-75

Bodor M, Santos RM, Kristova L, Elsen J, Vlad M, van Gerven T (2013) Susceptibility of mineral phases of steel slags towards carbonation: mineralogical, morphological and chemical assessment. Eur J Mineral 25:533-549

Bridge TE (1966) Bredigite, larnite and $\gamma$-dicalcium silicates from the Marble Canyon. Am Mineral 51:1766-1774

Bruker AXS (2018) DIFFRAC.TOPAS, version 6.0.0.9: General profile and structure analysis software for powder diffraction data. Bruker-AXS GmbH, Karlsruhe, Germany

Bruker-AXS (2020) DIFFRAC.EVA, version 5.2.0.5. Bruker-AXS $\mathrm{GmbH}$, Karlsruhe, Germany

Catti M, Gazzoni G, Ivaldi G (1984) Order-disorder in the $\alpha^{\prime}-(\mathrm{Ca}$, $\mathrm{Sr})_{2} \mathrm{SiO}_{4}$ solid solution: a structural and statistical-thermodynamic analysis. Acta Crystallogr B 40:537-544

Catti M, Ferraris G, Ivaldi G (1988) Thermal behavior of the crystal structure of strontian piemontite. Am Mineral 73:1370-1376

Chen M, Xia Z, Molokeev M, Liu Q (2015) Structural phase transformation and luminescent properties of $\mathrm{Ca}_{2-\mathrm{x}} \mathrm{Sr}_{\mathrm{x}} \mathrm{SiO}_{4}: \mathrm{Ce}^{3+}$ orthosilicate phosphors. Inorg Chem 54:11369-11376

Chiang YW, Santos RM, Monballiu A, Ghyselbrecht K, Martens JA, Mattos MLT, van Gerven T, Meesschaert B (2013) Effects of bioleaching on the chemical, mineralogical and morphological properties of natural and waste-derived alkaline materials. Miner Eng 48:116-125

Dezfuli SN, Huan Z, Mol A, Leeflang S, Chang J, Zhou J (2017) Advanced bredigite-containing magnesium-matrix composites for biodegradable bone implant applications. Mat Sci Eng C 79:647-660

Dörsam G, Liebscher A, Wunder B, Franz G, Gottschalk M (2007) Crystal chemistry of synthetic $\mathrm{Ca}_{2} \mathrm{Al}_{3} \mathrm{Si}_{3} \mathrm{O}_{12} \mathrm{OH}-\mathrm{Sr}_{2} \mathrm{Al}_{3} \mathrm{Si}_{3} \mathrm{O}_{12} \mathrm{OH}$ solid-solution series of zoisite and clinozoisite. Am Mineral 92:1133-1147

Douglas AMB (1952) X-ray investigation of bredigite. Mineral Mag $29: 875-884$

Farrugia LJ (1999) WinGX suite for small-molecule single-crystal crystallography. J Appl Crystallogr 32:837-838

Ferreira Neto JB, Fredericci C, Faria JOG, Chotoli FF, Ribeiro TR, Malynowskyj A, Silva ALN, Quarcioni VA, Lotto AA (2017) Modification of basic oxygen slag for cement manufacturing. J Sustain Metall 3:720-728

Grapes R (2011) Pyrometamorphism, 2nd edn. Springer, Heidelberg

Griffen DT, Ribbe PH, Gibbs GV (1977) The structure of slawsonite a strontium analog of paracelsian. Am Mineral 62:31-35

Gutt W (1961) A new calcium magnesiosilicate. Nature 190:339-340

Hoppe R (1979) Effective coordination numbers (ECoN) and mean fictive ionic radii (MEFIR). Z Kristallogr 150:23-52

Huang M, Zhang M, Yao D, Chen X, Pu X, Liao X, Huang Z, Yin G (2017) Dissolution behavior of $\mathrm{CaO}-\mathrm{MgO}-\mathrm{SiO}_{2}$-based bioceramic 
powders in simulated physiological environments. Ceram Int 13:9583-9592

Ilyushin GD, Blatov VA (2002) Crystal chemistry of zirconosilicates and their analogs: topological classification of MT frameworks and suprapolyhedral invariants. Acta Crystallogr B 58:198-218

Kahlenberg V, Galuskina I, Krüger B, Pauluhn A, Galuskin E (2019) Structural investigations on bredigite from the Hartrurim formation. Mineral Petrol 113:261-272

Lagache M, Dujon SC (1987) Distribution of strontium between plagioclase and 1 molar aqueous chloride solutions at $600^{\circ} \mathrm{C}, 1,5$ kbar and $750{ }^{\circ} \mathrm{C}, 2$ kbar. Bull Minéral 110:551-561

Liebau F (1985) Structural chemistry of silicates. Springer Verlag, Berlin

Momma K, Izumi F (2011) VESTA3 for three-dimensional visualization of crystal, volumetric and morphology data. J Appl Crystal$\operatorname{logr} 44: 1272-1276$

Moore PB, Araki T (1976) The crystal structure of bredigite and the genealogy of some alkaline earth orthosilicates. Am Mineral 61:74-87

Moseley D, Glasser FP (1981) Identity, composition and stability of bredigite phase T. Cement Concrete Res 11:559-565

Moseley D, Glasser FP (1982) Properties and composition of bredigitestructures phases. J Mater Sci 17:2736-2740

No YJ, Li JJ, Zeirat H (2017) Doped calcium silicate ceramics: a new class of candidates for synthetic bone substitutes. Materials 10:153

Ohsato H, Suzuki I, Kagomiya I (2017) Crystal structure and microwave dielectric properties of $\alpha-\left(\mathrm{Ca}_{1-\mathrm{x}} \mathrm{Sr}_{\mathrm{x}}\right) \mathrm{SiO}_{3}(\mathrm{x}=1$ and 0.8$)$ ring silicates for millimeter-wave applications. Mat Res Bull 96:115-120

Orobengoa D, Capillas C, Aroyo MI, Perez-Mato JM (2009) Amplimodes: symmetry-mode analysis on the Bilbao Crystallographic Server. J Appl Crystallogr 42:820-833

Palatinus L, Chapuis G (2007) SUPERFLIP - A computer program for the solution of crystal structures by charge flipping in arbitrary dimensions. J Appl Crystallogr 40:786-790

Pontikes Y, Kriskova L, Cizer Ö, Jones PT, Blanpain B (2013) On a new hydraulic binder from stainless steel converter slag. Adv Cem Res 25:21-31

Razavi M, Fathi M, Savabi O, Razavi SM, Beni BH, Vashaee D, Tayebi L (2013) Surface modification of magnesium alloy implants by nanostructured bredigite coating. Mater Lett 113:174-178

Rigaku (2015) CrysAlisPRO Software System, version 1.171.38.43. Rigaku Oxford Diffraction
Robinson K, Gibbs GV, Ribbe PH (1971) Quadratic elongation: a quantitative measure of distortion in coordination polyhedra. Science 172:567-570

Saalfeld $\mathrm{H}$ (1974) Kristallographische Untersuchungen über die Verbindung $\mathrm{Ca}_{7} \mathrm{MgSi}_{4} \mathrm{O}_{16}$ (Phase T) im System $\mathrm{Ca}_{2} \mathrm{SiO}_{4}-\mathrm{Ca}_{3} \mathrm{Mg}\left(\mathrm{SiO}_{4}\right)_{2}$. Ber Dt Keram Ges 51:295-298

Sharp JD, Johnson W, Andrews KW (1960) Visual method of primary slag control for the basic electric-arc furnace. J Iron Steel Inst 195:83-94

Sharygin VV, Sokol EV, Vapnik Y (2008) Minerals of the pseudobinary perovskite-brownmillerite series from combustion metamorphic larnite rocks of the Hartrurim Formation (Israel). Russ Geol Geophys 49:709-726

Sharygin VV (2010) Mineralogy of Ca-rich metacarbonate rocks from burned dumps of the Donetsk coal basin. In: Latest Developments in CoalFire Research. Bridging the Science, Economics, and Politics of a Global Disaster. Proc. ICCFR2-Second International Conference on Coal Fire Research. Berlin, Germany, pp 162-170

Sheldrick GM (2008) A short history of SHELX. Acta Crystallogr A 64:112-122

Stokes HT, Hatch DM (1988) Isotropy groups of the 230 crystallographic space groups. World Scientific, Singapore

Tilley CE, Vincent HCG (1948) The occurrence of an orthorhombic high-temperature form of $\mathrm{Ca}_{2} \mathrm{SiO}_{4}$ (bregidite) in the Scawt Hill contact-zone and as a constituent of slags. Mineral Mag 28:255-271

Wilson AJC (1992) International Tables for Crystallography Volume C Mathematical Physical and Chemical Tables, 1st edn. Kluwer Academic Publishers, Dordrecht

Wu C, Chang J, Wang J, Ni S, Zhai W (2005) Preparation and characteristics of a calcium magnesium silicate (bredigite) bioactive ceramic. Biomaterials 26:2925-2931

Yi D, Wu C, Ma B, Ji H, Zheng X, Chang J (2014) Bioactice bredigite coating with improved bonding strength, rapid apatite mineralization and excellent cytocompatibility. J Biomater Appl 28:1343-1353

Yonesaki Y (2015) (Ba, $\mathrm{Sr})_{3} \mathrm{MgSi}_{2} \mathrm{O}_{8}$ structure change caused by $\mathrm{Ba} /$ Sr replacement. Powder Diffr 30:40-51

Žáček V, Skála R, Dvořák Z (2015) Combustion metamorphism in the Most Basin. In: Stracher G, Prakash A, Sokol EV (eds) Coal and peat fires: a global perspective, vol 3, 1st edn. Case studies. Elsevier, Amsterdam, pp 162-202

Publisher's Note Springer Nature remains neutral with regard to jurisdictional claims in published maps and institutional affiliations. 